\title{
Evaluation of the Effect of Alloy
} Chemistry on the Susceptibility of Weld Solidification Cracking of Alloy 709 Weldment and Development of

\section{Mitigation Strategy}

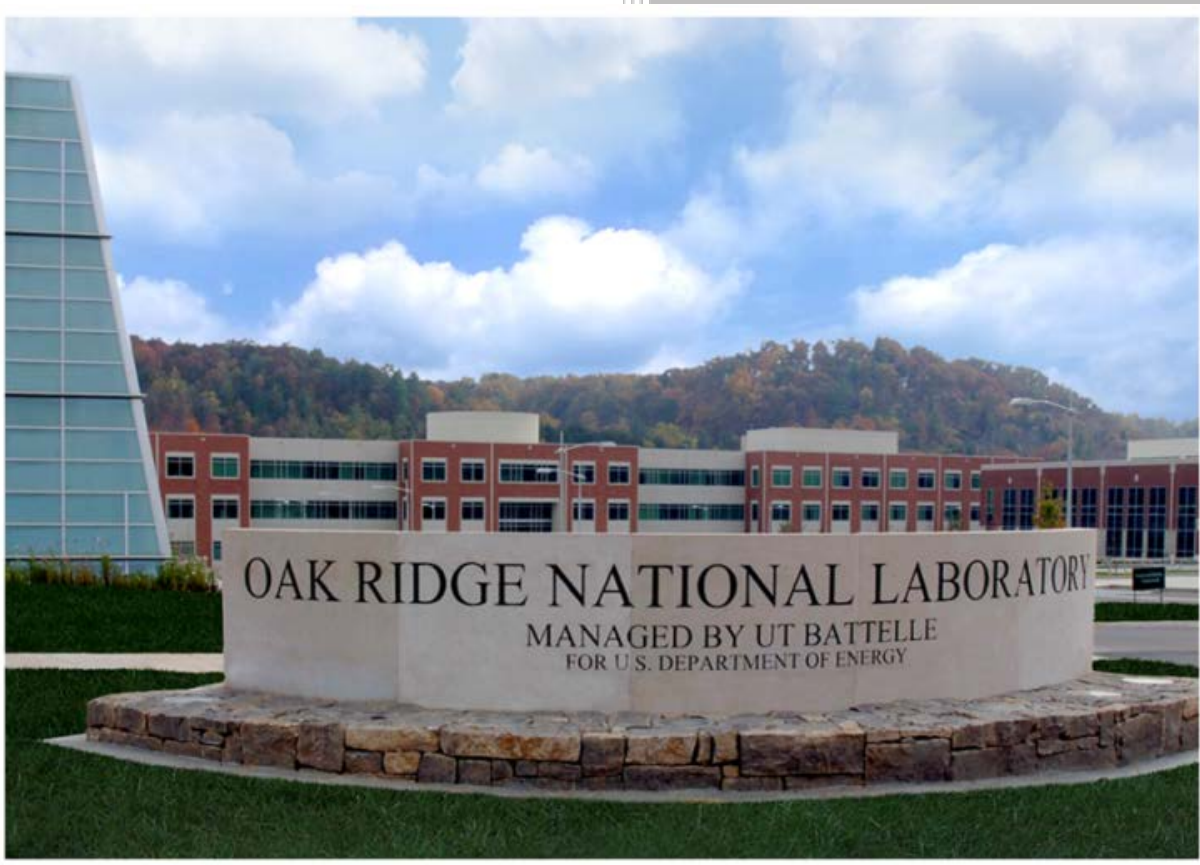

Zhili Feng John M. Vitek Tingkun Liu Yanli Wang

September 14, 2018

Approved for public release. Distribution is unlimited. 


\title{
DOCUMENT AVAILABILITY
}

Reports produced after January 1, 1996, are generally available free via US Department of Energy (DOE) SciTech Connect.

\section{Website http://www.osti.gov/scitech/}

Reports produced before January 1, 1996, may be purchased by members of the public from the following source:

\author{
National Technical Information Service \\ 5285 Port Royal Road \\ Springfield, VA 22161 \\ Telephone 703-605-6000 (1-800-553-6847) \\ TDD 703-487-4639 \\ Fax 703-605-6900 \\ E-mail info@ntis.gov \\ Website http://www.ntis.gov/help/ordermethods.aspx
}

Reports are available to DOE employees, DOE contractors, Energy Technology Data Exchange representatives, and International Nuclear Information System representatives from the following source:

Office of Scientific and Technical Information

PO Box 62

Oak Ridge, TN 37831

Telephone 865-576-8401

Fax 865-576-5728

E-mail reports@osti.gov

Website http://www.osti.gov/contact.html

This report was prepared as an account of work sponsored by an agency of the United States Government. Neither the United States Government nor any agency thereof, nor any of their employees, makes any warranty, express or implied, or assumes any legal liability or responsibility for the accuracy, completeness, or usefulness of any information, apparatus, product, or process disclosed, or represents that its use would not infringe privately owned rights. Reference herein to any specific commercial product, process, or service by trade name, trademark, manufacturer, or otherwise, does not necessarily constitute or imply its endorsement, recommendation, or favoring by the United States Government or any agency thereof. The views and opinions of authors expressed herein do not necessarily state or reflect those of the United States Government or any agency thereof. 
Materials Science and Technology Division

EVALUATION OF THE EFFECT OF ALLOY CHEMISTRY ON THE SUSCEPTIBILITY OF WELD SOLIDIFICATION CRACKING OF ALLOY 709 WELDMENT AND DEVELOPMENT OF MITIGATION STRATEGY

Zhili Feng, John M. Vitek, Tingkun Liu, Yanli Wang

September 14, 2018

Prepared by OAK RIDGE NATIONAL LABORATORY

Oak Ridge, TN 37831-6283

managed by

UT-BATTELLE, LLC

for the

US DEPARTMENT OF ENERGY

under contract DE-AC05-00OR22725 



\section{CONTENTS}

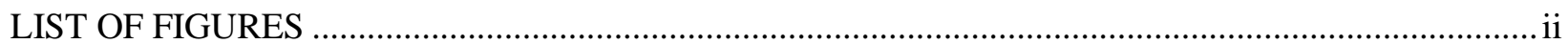

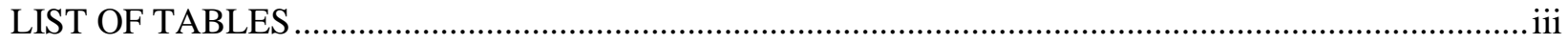

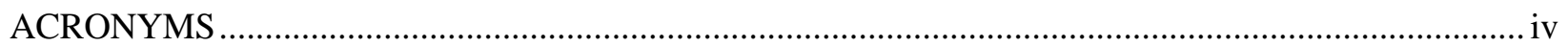

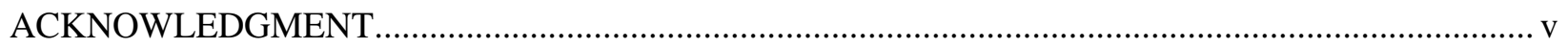

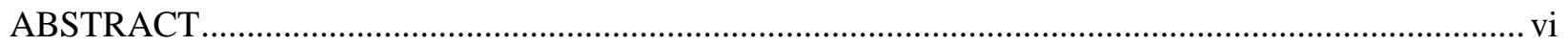

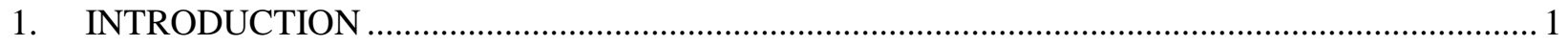

2. EVALUATE THE EFFECT OF ALLOY CHEMISTRY THROUGH THERMODYNAMIC

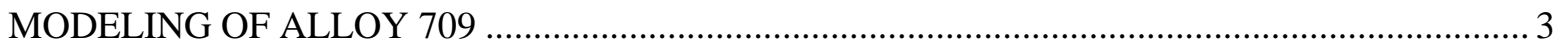

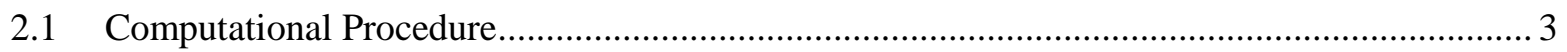

2.2 Alloy Compositions for Thermodynamic Analysis ................................................................ 4

2.3 Overall Phase Stability in Alloy 709 during Solidification ................................................... 4

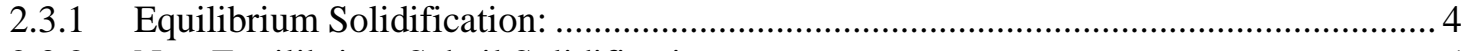

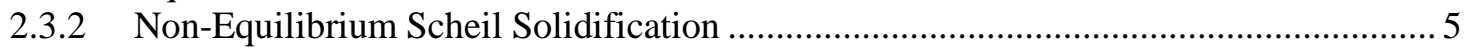

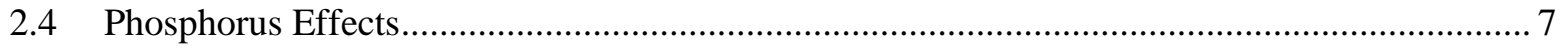

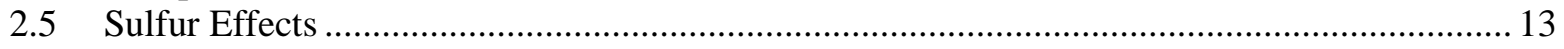

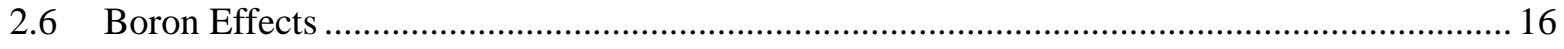

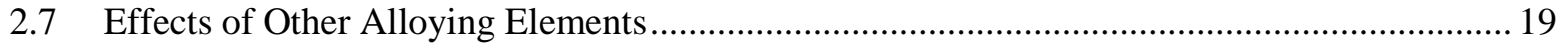

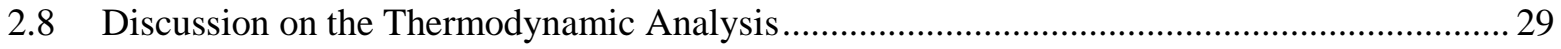

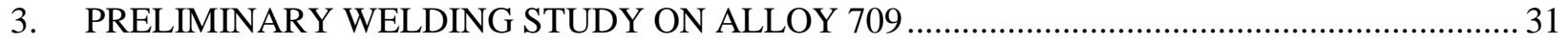

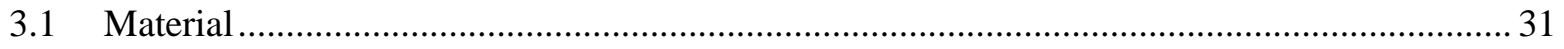

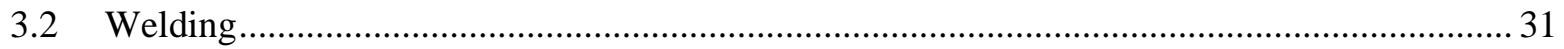

3.3 Qualification Testing of Welds for Alloy 709 AOD SA1100 Plate......................................... 33

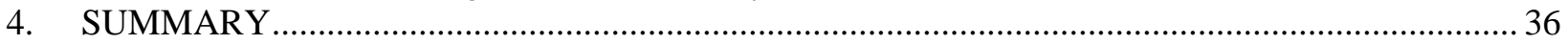

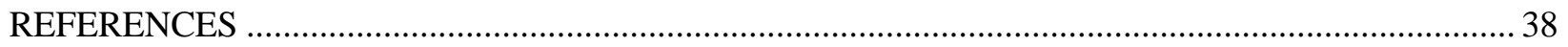




\section{LIST OF FIGURES}

Figure 1 General non-equilibrium solidification sequence of two Alloy 709 heats. ............................ 6

Figure 2 Effect of P level on the solidus temperatures for equilibrium solidification, and non-

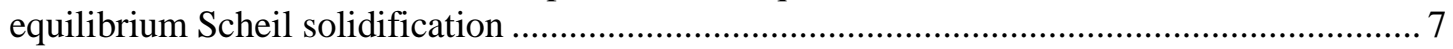

Figure 3 Effect of P level on the phosphide start temperature, and the effective solidus....................... 8

Figure 4. $\quad \mathrm{P}$ distribution among various phases as a function of temperature for Scheil

simulationof "average" alloy with 0.006 wt \% P......

Figure 5. Plot of $\mathrm{P}$ distribution among all phases present during Scheil simulation as a function

of temperature for alloy YT709. P content of alloy is high (0.018 wt \%)............................... 10

Figure 6. Liquid composition versus temperature for Scheil simulation of "average” alloy but with only 0.006 wt \% P.

Figure 7. Liquid composition versus temperature for Scheil simulation of "average" alloy but with $0.015 \mathrm{wt} \% \mathrm{P}$. 12

Figure 8. Scheil effective solidus temperatures vs. P content for a wide range of alloys...................... 12

Figure 9. Plot of S distribution among various phases during Scheil solidification of "average" alloy (but with only $0.006 \mathrm{wt} \% \mathrm{P}$ ).

Figure 10. Liquid composition as a function of temperature for Scheil solidification of "average" alloy but with maximum allowed S content (0.01 wt \%).

Figure 11. B distribution among the various phases as a function of temperature for the Scheil simulation of "average" alloy but with only 0.006 wt \% P.

Figure 12. Liquid composition versus temperature for Scheil simulation of "average" alloy but with maximum B (0.01 wt \%).

Figure 13. Distribution of $\mathrm{Cr}$ among the various phases as a function of temperature for Scheil simulation of "average" alloy with $0.006 \mathrm{wt} \% \mathrm{P}$.

Figure 14. Distribution of Ni among the various phases as a function of temperature for Scheil simulation of "average" alloy with 0.006 wt \% P. 21

Figure 15. Distribution of Mn among the various phases as a function of temperature for Scheil simulation of "average" alloy with $0.006 \mathrm{wt} \% \mathrm{P}$.

Figure 16. Distribution of Si among the various phases as a function of temperature for Scheil simulation of "average" alloy with 0.006 wt \% P.

Figure 17. Distribution of Mo among the various phases as a function of temperature for Scheil simulation of "average" alloy with $0.006 \mathrm{wt} \% \mathrm{P}$.

Figure 18. Distribution of $\mathrm{Nb}$ among the various phases as a function of temperature for Scheil simulation of "average" alloy with 0.006 wt \% P.

Figure 19. Distribution of Ti among the various phases as a function of temperature for Scheil simulation of "average" alloy with $0.006 \mathrm{wt} \% \mathrm{P}$.

Figure 20. Distribution of $\mathrm{C}$ among the various phases as a function of temperature for Scheil simulation of "average" alloy with $0.006 \mathrm{wt} \% \mathrm{P}$.

Figure 21. Distribution of $\mathrm{N}$ among the various phases as a function of temperature for Scheil simulation of "average" alloy with $0.006 \mathrm{wt} \% \mathrm{P}$. 28

Figure 22. As-received Alloy 709 AOD SA1100 plate (a) and after surface preparation (b) .................. 31

Figure 23 Groove Design and weld-pass layout of the initial welding experiment............................... 33

Figure 24. Multi-pass V-groove weld for Alloy 709 AOD SA1100 plate............................................. 33

Figure 25. Dye penetrant inspection of the bead on plate welds and multi-pass V groove weld ............. 34

Figure 26. X-ray inspection of the bead on plate welds and multi-pass V groove weld ......................... 35

Figure 27. Side bend test specimens of the multi-pass V groove weld on Alloy 709 ............................. 35 


\section{LIST OF TABLES}

Table 1. Alloy compositions and variations (in parentheses) considered............................................. 4

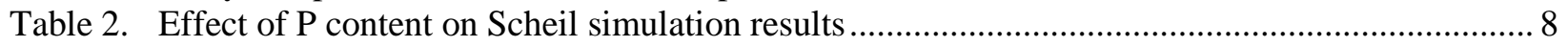

Table 3. Effect of changes in S content on Scheil effective solidus temperature .................................... 13

Table 4. Effect of changes in B content on the boride formation temperature and the solidus temperature under equilibrium and Scheil conditions ........................................................... 16

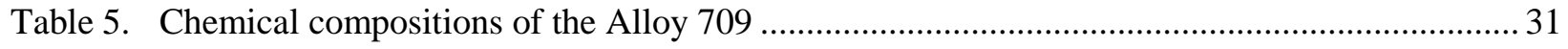




\section{ACRONYMS}

AOD Argon-Oxygen-Decarburization

ART Advanced Reactor Technologies

ASME

ASTM

BTR

DOE

GTAW

FCC

ORNL

SFR

The American Society of Mechanical Engineers

American Society for Testing and Materials. (aka, ASTM International)

Brittle Temperature Range

Department of Energy

Gas Tungsten Arc Welding

Face Centered Cubic

Oak Ridge National Laboratory

Sodium Fast Reactor 


\section{ACKNOWLEDGMENT}

The research was sponsored by the U.S. Department of Energy, under contract No. DE-AC05-

00OR22725 with Oak Ridge National Laboratory (ORNL), managed and operated by UT-Battelle, LLC. Programmatic direction was provided by the Office of Nuclear Energy.

The authors gratefully acknowledge the support provided by Alice Caponiti, Director, Office of Advanced Reactor Technologies (ART), Sue Lesica, Federal Manager, ART Advanced Materials Program, Robert Hill of ANL, National Technical Director, ART Fast Reactors Campaign, and Sam Sham of ANL, ART Technology Area Lead on Advanced Materials.

The authors acknowledge the support by Doug Kyle of ORNL in performing welding and qualification testing. George Young of Dominion Engineering Inc for valuable discussions and suggestions on the computational model analysis of the work. The time spent by Jian Chen and Lianshan Lin of ORNL in reviewing this report is greatly appreciated. 


\begin{abstract}
Alloy 709 is an attractive candidate construction material for Sodium Fast Reactor. As part of the Alloy 709 Intermediate Term Test Program, this work covers the development of the technical basis for welding fabrication and weld qualification of Alloy 709. The phase of research reported herein focused on the issue of weld solidification cracking recently experienced in some experimental heats of Alloy 709 with relatively high P levels. To this end, computational thermodynamics simulations were used to investigate the solidification behavior of Alloy 709. The roles of alloying elements, in particular the impurity elements P, S, and B on solidification behavior and susceptibility of weld solidification cracking were systematically analyzed and identified using the computational simulation model. To simulate the solidification during welding conditions, Scheil simulations of non-equilibrium solidification were performed. Equilibrium calculations were also made for comparison. It was found that the impacts of variations in the P content wer major. Increasing levels of P from 0.002 to $0.018 \mathrm{wt} \%$ led to a decrease in the solidus temperature of over $300^{\circ} \mathrm{C}$ (solidus in Scheil simulations is chosen at the temperature where the fraction liquid $<0.1 \%$ ). Thus, $\mathrm{P}$ has the most important impact on solidification behavior. High levels of phosphorous lead to very large increases in the non-equilibrium solidification temperature range. Thus, $\mathrm{P}$ is expected to significantly increase the susceptibility of weld solidification cracking of Alloy 709. This conclusion was supported by limited experimental data that showed poor weldability and cracking for the 709 alloy with high P levels (0.018 wt \% P).
\end{abstract}

Compared to P, the effects of other elements are relatively minor. Variations in S content have little impact on the solidification behavior and the solidification temperature range when $\mathrm{P}$ is present. Changes in B content had a relatively minor impact on the solidification temperature range. As the boron content increased to the maximum allowed in the alloy specifications $(0.01 \mathrm{wt} \%)$, the solidus temperature was extended to lower temperatures by as much as $40^{\circ} \mathrm{C}$. The majority of elements ( $\mathrm{Cr}, \mathrm{Ni}, \mathrm{Mn}, \mathrm{Si}, \mathrm{Mo}, \mathrm{Nb}$, $\mathrm{Ti}, \mathrm{C}, \mathrm{N}$ ) are partitioned to solid phases that are stable at relatively high temperatures (TiN, austenite, $\mathrm{M}_{23} \mathrm{C}_{6}$, and $\mathrm{Nb}(\mathrm{C}, \mathrm{N})$ ). Therefore, these elements are not likely to extend the solidification temperature range on the low temperature side and it is presumed that they are not of primary concern with regard to the weldability.

The knowledge obtained from the computational modeling above leads to the development to strategies to weld heats of Alloy 709 having wide range of chemistry without weld solidification cracking to support code qualification. One of the approaches was to use low P level matching weld wire to weld relatively high P Alloy 709. The potential of this approach has been demonstrated with initial success in fabricating a Section IX qualified weld on the first commercial heat (Carlson 58776) having relatively high P (0.014 wt $\%, 140 \mathrm{wppm}$ ) using a $0.002 \mathrm{wt} \%$ (20 wppm) low P matching weld wire. Inspection and side bend tests on this multi-pass weld confirmed that it passed the ASME Section IX qualification requirement. This report summaries these preliminary experimental results.

This report fulfills the FY18 milestone M3NT-18OR050502023 - "Complete the evaluation of the effect of alloy chemistry on the susceptibility of weld solidification cracking of Alloy 709 weldment and fabricate initial test welds” under the ORNL work package NT-18OR05050202 - “A709 Development ORNL". 


\section{INTRODUCTION}

Advanced materials can have a significant impact on flexibility, safety, and economics of future sodium fast reactor (SFR). This is due to innovative designs and design simplifications that could be made possible using materials with enhanced mechanical properties. Improved materials performance also impacts safety through improved reliability and greater design margins. Improved material reliability could also result in reduced down time.

Alloy 709 is an advanced nitrogen-stabilized and niobium-strengthened austenitic stainless steel. Compared to reference construction material 361H stainless steel for SFR, Alloy 709 has enhanced creep strength, good steam oxidation resistance and hot corrosion resistance. It is an attractive candidate construction material for SFR systems (Busby et al., 2008). Code qualification of Alloy 709 is underway as part of the Advanced Materials Development program (Sham and Natesan, 2017), to provide the technical basis needed to support the regulatory requirements for structural materials required for advanced, non-light water reactors that could be deployed in the near-to-mid-term.

Alloy 709 is derived from NF709, i.e., TP310MoCbN (UNS S31025) specified in ASTM A213-15C. NF709 seamless tube was developed by Nippon Steel Corporation in Japan for boiler tubing applications. Previous studies such as these by Nippon Steel (Nippon Steel, 2013), suggested that NF709 has relatively good weldability. Alloy 709 matching filler metal and Alloy 625 filler metal were the two weld metals that Nippon Steel had recommended to weld seamless tubing. Performance of Alloy 709 weldment fabricated using Alloy 625 filler metal in sodium was found to be less than optimal during the Alloy 709 intermediate term testing program because of the high solubility of nickel in sodium. Weldment fabricated from Alloy 709 matching filler metal was found to have good sodium compatibility. However, more recent welding studies on experimental heats of Alloy 709 in plate form at ORNL (Yamamoto, 2014) revealed potential issues of weld solidification cracking when the level of impurity such as $P$ is high but still within the ASTM A-213-15C specification. A number of weldments using Alloy 709 matching filler metal with different chemical compositions were fabricated by ORNL and only the weldment with very low P content (less than $20 \mathrm{wppm}$, or $0.002 \mathrm{wt} \%$ ) in both the base metal (plate form) and the matching filler metal passed the ASME Section IX weldment qualification test. Cracks were found in all the other weldments. While a Section IX qualified weldment was fabricated successfully, the requirement of very low $\mathrm{P}$ content (20wppm) places a severe restriction.

Welding is essential in construction of SFR structures. The purpose of this study is to develop the technical basis for welding of Alloy 709 to support the code case qualification for SFR. The anticipated deliverable includes welding guidelines and testing results to fabricate ASME Section IX qualified welds using weld wires with appropriately specified chemistry range, to eliminate stress relaxation cracking issues, and to retain the good cross-weld creep rupture performance, for selected plate heats meeting the chemistry specifications of ASTM A213-15C for TP310MoCbN (UNS S31025) seamless tubing.

The objective of this work was to conduct a fundamental study to determine if the severe restriction on the P content can be relaxed. To this end, computational solidification simulation modeling was first carried out to evaluate, understand and quantify the effect of impurity on weld solidification cracking of Alloy 709. Using the results from the computational modeling as guidance, a screening assessment was carried out to determine the feasibility of welding a commercial heat Alloy 709 (Carlson 58776) with relatively high P level (140wppm) with relatively low P level (20wppm) matching weld wire. The lessons learned in this screening welding trials, together with the computational weld modeling results, will be used to refine or apply innovative welding techniques to produce ASME Section IX qualified welds potentially covering the chemistry range per ASTM A213-15C. 
This report summarizes the computational thermodynamics simulations results on the sonification behavior and initial experimental results on welding of the commercial heat Alloy 709 plate. 


\section{EVALUATE THE EFFECT OF ALLOY CHEMISTRY ON THE SUSCEPTIBILITY OF WELD SOLIDIFICATION CRACKING THROUGH THERMODYNAMIC MODELING OF ALLOY 709}

Extensive research in the past on stainless steels and nickel based super alloys have established the highlevel impurities such as P and S would increase the susceptibility or likelihood of solidification cracking (or hot cracking) in welding of these alloys. According to solidification theory, solidification of the molten metal in the weld pool is a non-equilibrium process. Solute including impurity rejection at the microscopic solidification front would result in micro-segregation of various elements, which can greatly change the non-equilibrium solidification temperature range. The concept of Brittle Temperature Range (BTR), which is closely related to the non-equilibrium solidification temperature range, has been widely used to as a metallurgical indicator or qualifier for the susceptibility of solidification cracking (Feng, 1993). In this study, the non-equilibrium solidification temperature range and BTR was evaluated using thermodynamic solidification modeling tools, as function of key alloying elements and impurity (P and S) that are permissible per ASTM specification of Alloy 709. It was to develop necessary understanding of the roles of impurity level and alloy elements that would contribute to the susceptibility of weld solidification cracking. This understanding would help strategize means to weld heats of Alloy 709 having wide range of chemistry without weld solidification cracking to support the code qualification.

\subsection{COMPUTATIONAL PROCEDURE}

The ThermoCalc software (version 2017b) was used for most of the calculations. The Scheil solidification model was used to carry out the simulation of solidification behavior during welding. The Scheil model considers perfect diffusion in the liquid but no diffusion in the solid as the temperature is decreased. It is a well-accepted approximation for weld solidification due to the fact that (1) the relatively fast cooling rate during welding limits the solid-state diffusion of alloying elements (other than carbon, boron), and (2) strong molten metal flow during welding tends to homogenize the chemical composition in the molten weld pool. In Scheil solidification calculations, the solidification during an incremental drop in temperature (typically $1^{\circ} \mathrm{C}$ ) is evaluated. Any solid that already formed is not allowed to undergo any changes (either in stability or composition) during subsequent cooling. The remaining liquid is assumed to be homogeneous and the process is repeated by decreasing the temperature again. The simulation was continued until the fraction liquid $\left(\mathrm{f}_{\mathrm{L}}\right)<0.001$ (i.e., $<0.1 \%$ liquid). It was found that using this limit (rather than the more common 1\% liquid) enhanced the impact of small variations in alloy content. Equilibrium calculations of the solidification sequence were made for comparison.

The most current version of ThermoCalc database, TCFE9, at the time of the calculations was used. This database was particularly suited for the calculations because in the latest database revisions, improvements were specifically made in the models for $\mathrm{P}$ and $\mathrm{S}$ effects. Other calculations using older databases were also made for comparison. In general, the results were similar, but only results from calculations using TCFE9 are presented here.

Some calculations were also performed using the JMatPro software (version 9). Once again, the results were generally the same as those found using ThermoCalc. However, simulations using ThermoCalc were preferred for two reasons. First, the latest ThermoCalc database was specifically updated with respect to the modeling of $\mathrm{S}$ and $\mathrm{P}$, and these constituents are expected to have significant impacts on the welding behavior. Second, JMatPro did not allow for the consideration of B and S in the alloy composition. 


\subsection{ALLOY COMPOSITIONS FOR THERMODYNAMIC ANALYSIS}

A literature survey yielded the chemical composition over 35 different heats of Alloy 709. Further, previous study at ORNL (Yamamoto, 2014) has detailed description of the experimental heats and the weld wires that exhibited solidification cracking during weld (high P level) and no cracking (low P level). Hence, the computational simulation of solidification behavior first focused on three alloy compositions in greatest details: Heat "YT709" which showed cracking during welding, Heat 120138 which did not show cracking during welding, and Heat "Average" which is the average composition over the 35 different heats collected from literature. Variations of these three alloy compositions were then examined. The P, S, and B contents were varied, and in some cases, the Mn content was changed. The alloy compositions and the ranges in composition variations are shown in Table 1. A few other compositions were evaluated as well. Results from these other alloys were comparable to the results for the alloys listed in Table 1, showing the same trends, and they will not be considered in detail.

\begin{tabular}{|c|c|c|c|}
\hline \multicolumn{4}{|c|}{ Table 1. Alloy compositions and variations (in parentheses) considered (compositions in wt \%). } \\
\hline Element & Heat YT709 & Heat 120138 & Heat Average \\
\hline $\mathrm{Cr}$ & 20.18 & 22.10 & 20.8 \\
\hline $\mathrm{Ni}$ & 25.13 & 25.02 & 24.8 \\
\hline $\mathrm{Mn}$ & 0.93 & $0.97(0.1-0.97)$ & 1.04 \\
\hline $\mathrm{Si}$ & 0.38 & 0.36 & 0.4 \\
\hline $\mathrm{Mo}$ & 1.49 & 1.49 & 1.47 \\
\hline $\mathrm{Nb}$ & 0.25 & 0.25 & 0.25 \\
\hline $\mathrm{Ti}$ & 0.05 & 0.05 & 0.06 \\
\hline $\mathrm{B}$ & $0.003(0.001-0.01)$ & $0.0036(0.001-0.01)$ & $0.004(0.004-0.01)$ \\
\hline $\mathrm{C}$ & 0.069 & 0.043 & 0.055 \\
\hline $\mathrm{N}$ & 0.147 & 0.174 & 0.17 \\
\hline $\mathrm{P}$ & $0.018(0.003-0.018)$ & $0.002(0.002-0.015)$ & $0.009(0.006-0.015)$ \\
\hline $\mathrm{S}$ & $0.0005 *(0.0005-0.01)$ & $0.0005 *(0.0005-0.01)$ & $0.001(0.001-0.01)$ \\
\hline
\end{tabular}

\subsection{OVERALL PHASE STABILITY IN ALLOY 709 DURING SOLIDIFICATION}

The overall features of phase formation during solidification are summarized here. More detailed results on the effects of B, S, and P are described in separate sections below.

\subsubsection{Equilibrium Solidification:}

The first phase to form under equilibrium conditions is TiN (with very minor amounts of other elements). Upon cooling, TiN becomes stable in the range of 1485 to $1515^{\circ} \mathrm{C}$, but with high Ti levels it may form at temperatures as high as $1617^{\circ} \mathrm{C}$. The amount of TiN that forms is relatively small, on the order of $<0.1 \%$. In the case of high Ti levels, the amount of TiN may reach $0.2 \%$. The second phase to form is austenite which has face centered cubic (FCC) crystalline structure, and so labeled accordingly in the figures showing the ThermoCalc simulation results below. The FCC austenite becomes stable at approximately $1400^{\circ} \mathrm{C}\left(+/-5^{\circ} \mathrm{C}\right)$ for all of the compositions examined. Austenite is the major phase that forms under equilibrium conditions, with over $90 \%$ austenite forming over the next $100^{\circ} \mathrm{C}$. At the solidus, the amount of austenite is $>95 \%$. Before the equilibrium solidification is complete, two other minor phases are stable: a Nb-rich carbo-nitride and MnS.

For all compositions studied, solidification is complete in the range of $1258-1298^{\circ} \mathrm{C}$ with a couple of exceptions. If the boron level is very low or set to 0 , solidification is complete at temperatures $>1300^{\circ} \mathrm{C}$. 
On the other hand, if B is set to the maximum allowed ( $0.01 \mathrm{wt} \%, 100 \mathrm{wppm})$, solidification is not complete until the boride $\mathrm{M}_{2} \mathrm{~B}$ is stable and forms, typically around $1210^{\circ} \mathrm{C}$. The results indicate that as the $\mathrm{B}$ level increases, solidification may be delayed until $\mathrm{M}_{2} \mathrm{~B}$ is stable and $\mathrm{B}$ can be absorbed by the boride.

It is noteworthy that raising the $\mathrm{S}$ level to as high as the maximum allowed $(0.01 \mathrm{wt} \%)$ does not affect the equilibrium solidus temperature. MnS is typically stable just above $1300^{\circ} \mathrm{C}$ and thus, unlike the case for B, the solidus is not depressed until MnS can form. Even if the Mn level is decreased, the solidus does not drop; in fact, as the Mn is lowered the solidus increases slightly.

Also of importance is that under equilibrium conditions, high $\mathrm{P}$ levels do not affect the equilibrium solidus very much. This is very different than the solidification behavior found under non-equilibrium Scheil conditions, as described later. Increasing the P level from $0.003 \mathrm{wt} \%$ to $0.018 \mathrm{wt} \%$ in alloy YT709 led to a drop in the solidus of only $11^{\circ} \mathrm{C}$ while increasing the $\mathrm{P}$ level in alloy 120138 from 0.002 $\mathrm{wt} \%$ to $0.015 \mathrm{wt} \%$ led to a drop in the equilibrium solidus of $13^{\circ} \mathrm{C}$. What is critically important is that under equilibrium conditions, in which the $\mathrm{P}$ content of austenite is allowed to increase as the solubility of $\mathrm{P}$ in austenite increases with decreasing temperature, even high levels of $\mathrm{P}$ can be totally absorbed by the austenite. This is because complete diffusion of $\mathrm{P}$ across all of the austenite, including austenite formed at high temperatures, is allowed. $\mathrm{P}$ is basically insoluble in all other solid phases found in equilibrium.

\subsubsection{Non-Equilibrium Scheil Solidification}

The solidification sequence under non-equilibrium Scheil conditions is considerably different and more complex. In a Scheil solidification simulation, the compositions of the solid phases that from at any given temperature are frozen and are not allowed to adjust as the temperature drops and the solid solubility of any solute may change. Furthermore, any solid that formed remains as the temperature decreases, even if solid that formed at higher temperatures is unstable at lower temperatures.

The overall solidification sequence and formation of different phases at different temperature ranges are illustrated in Figure 1, for two experimental weld wires with different levels of P. Heat 12013086-709 had 20wppm P, and YT709-ORNL had 180 wppm P. The early stages of solidification under Scheil conditions are basically identical to those found under equilibrium conditions. TiN solidifies first, generally less than $0.3 \mathrm{wt} \%$ for all cases simulated. FCC austenite formation follows, and since the amount of TiN is small and does not affect the overall composition to any significant degree, the austenite formation temperature is basically the same as under equilibrium conditions. Austenite is the major phase to form as solid, comprising approximately $95 \%$ or more of the final solid. MnS and Nb-rich carbo-nitride also form during cooling. However, many other phases are predicted to form under non-equilibrium conditions. After austenite, $\mathrm{M}_{23} \mathrm{C}_{6}$ is the most abundant phase that forms during Scheil solidification, with amounts of $\approx 1-2 \%$ predicted. Other phases that may form include BCC ferrite, $\sigma$ phase, $\mathrm{Z}$ phase, an HCP phase, and $M_{3} B_{2}$ boride. In fact, the $M_{3} B_{2}$ boride is the more common boride predicted. The $M_{2} B$ boride predicted under equilibrium conditions is only found when the B content is high. In addition, at high $\mathrm{P}$ levels, $\mathrm{M}_{3} \mathrm{P}$ phosphide is predicted to form. All phases other than austenite and $\mathrm{M}_{23} \mathrm{C}_{6}$ are found in small amounts, typically $<0.5 \%$.

A true solidus is not achieved in the Scheil simulation. Instead, Scheil solidification simulations continue until the fraction liquid $\left(f_{\mathrm{LI}}\right)$ drops below a preset termination amount. In this investigation, the Scheil simulations were extended to $f_{\mathrm{LIQ}}<0.001$ (i.e., $0.1 \%$ ). As noted below, by extending the calculations to 0.001 fraction liquid, the effect of $\mathrm{P}$ was exaggerated. Throughout this report, the end of solidification under Scheil conditions is referred to as the "effective solidus", denoting that it is not a true solidus. 
Since only a very small amount of TiN forms at high temperature (before the formation of austenite), TiN would practically have no contributions to the solidification cracking. For this reason, an "effective" solidification temperature range is used to evaluate the effect of chemistry on the susceptibility of the solidification cracking in Alloy 709. The effective solidification temperature range is the temperature range from the incipient of austenite formation to when $99.9 \%$ of metal solidifies (i.e., $0.1 \%$ of liquid still remains).

Figure 1 compares the solidification sequence and solidification temperature range of two experimental heats with 180wppm and 20wppm P levels. Clearly, the high P heat (YT709-ORNL) has a wider effective solidification temperature range, and a lower effective solidus, thereby higher susceptibility for solidification cracking which is consistent with the actual weld cracking behaviors observed before (Yamamoto, 2014).

Figure 2 summarizes the differences in equilibrium solidification solidus and the effective solidus under Scheil solidification as function of P level, for a subset of chemistry simulated in this work. As shown in the figure, the $\mathrm{P}$ level is very limited influence on the equilibrium solidus, but strongly influence the nonequilibrium solidus that is likely to occur in welding. Perhaps the most important finding from the simulation is that as the $P$ level increases, the effective solidus decreases nearly linearly. The effective solidus decreases to about $700 \mathrm{C}$ when the $P$ concentration in a heat reaches $0.02 \mathrm{wt} \%$ (200 wppm).

Such a low solidus temperature would highly likely cause weld solidification cracking. In other words, the level of $P$ in the weld metal would need to be reduced or controlled in order to produce sound defect free welds.

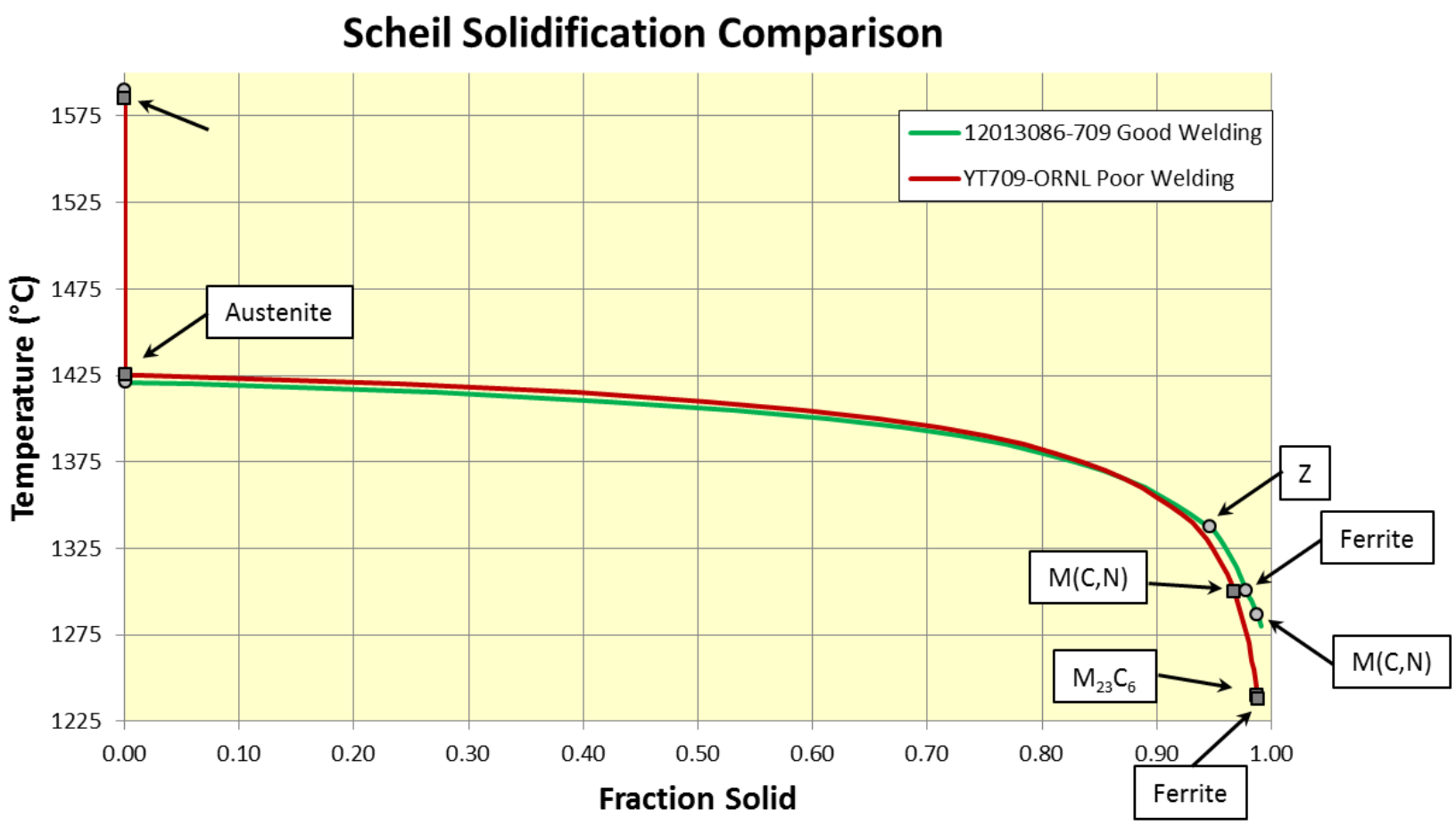

Figure 1 General non-equilibrium solidification sequence of two Alloy 709 heats, as predicted by Scheil model. The calculations were terminated at $1 \%$ of liquid remaining. 


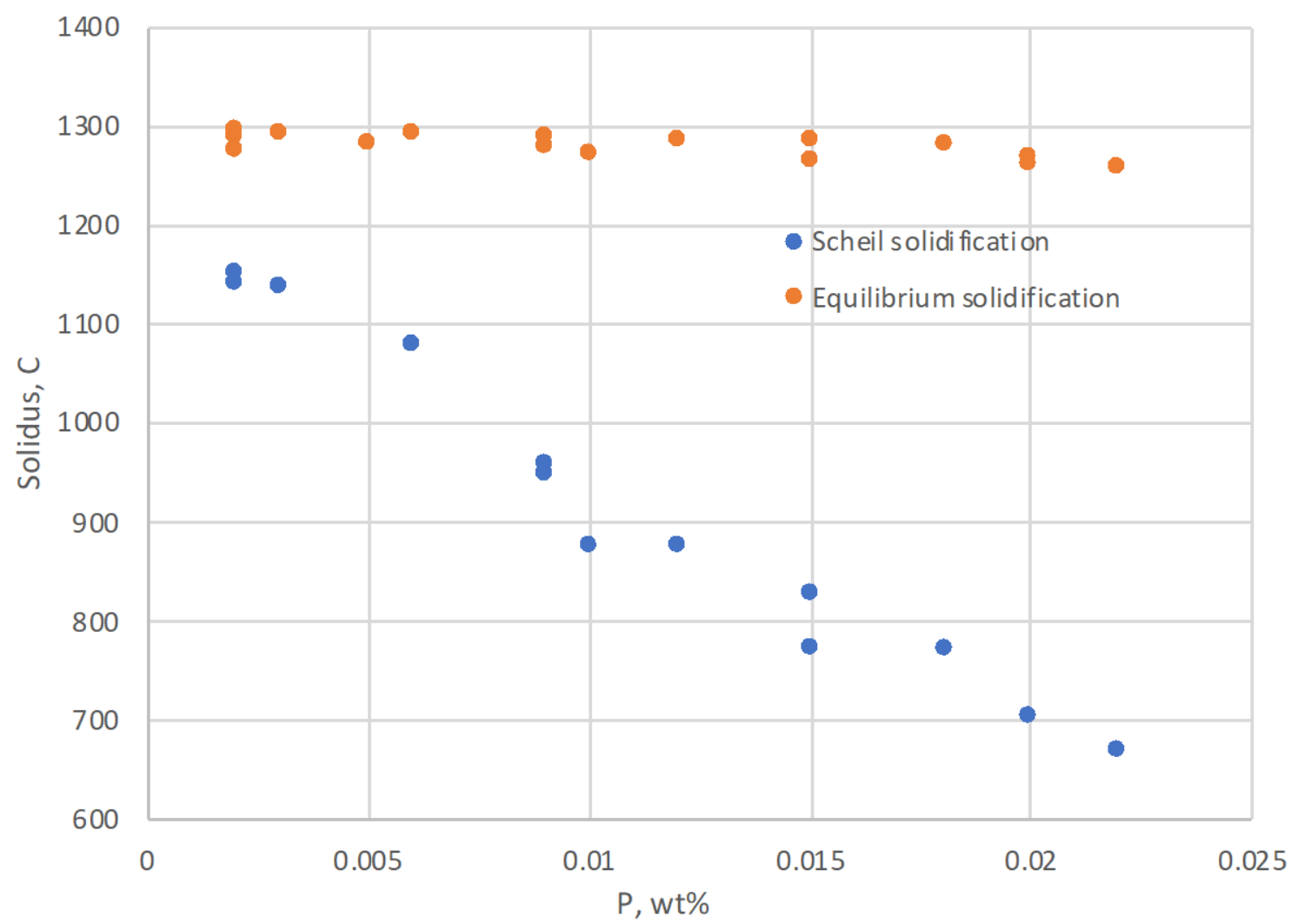

Figure 2 Effect of $P$ level on the solidus temperatures for equilibrium solidification, and nonequilibrium Scheil solidification (terminated at $0.1 \%$ liquid phase)

\subsection{PHOSPHORUS EFFECTS}

The causes and mechanisms for the aforementioned detrimental P effects (Figure 2) are further discussed in this section.

Under equilibrium conditions, phosphide does not form at any of the P levels studied (note that the highest P level for the alloys examined, as listed in Table 1 , was $0.018 \mathrm{wt} \%$, and not the maximum allowed in the alloy specifications, $0.03 \mathrm{wt} \%$ ). Thus, even though $\mathrm{P}$ is rejected back into the liquid during equilibrium solidification, the solubility of $\mathrm{P}$ in austenite, which increases as the temperature decreases, is sufficient to absorb all the P in austenite even at the higher P level (0.018 wt \%).

The behavior under Scheil conditions is different from that found under equilibrium conditions. Much more $\mathrm{P}$ is rejected back into the liquid under non-equilibrium solidification. Thus, even though the solubility of $\mathrm{P}$ in austenite increases with decreasing temperature, most of the $\mathrm{P}$ remains in the liquid. Under Scheil solidification conditions, the bulk of the austenite forms at high temperatures where the solubility of $\mathrm{P}$ is limited. Phosphides become stable or start to form at much lower temperatures (around $900^{\circ} \mathrm{C}$ ). Consequently, the Scheil simulation is extended until one of two conditions takes place. The first condition is that solidification proceeds to lower temperatures until the cutoff of $0.1 \%$ remaining liquid is reached and the simulation is terminated. The second condition is that the simulation proceeds until phosphides become stable (i.e. start to form) before the liquid fraction decreases to $0.1 \%$ so there is an outlet for the excessive $\mathrm{P}$ that has built up in the liquid. The results for several alloys are shown in Table 4 where the phosphide formation temperatures and Scheil effective solidus are listed. Note that many 
variants of the base compositions were simulated to identify the effect of P content in detail. The effect of $\mathrm{P}$ is also shown in Figure 3, which provides a better illustration of the effect of $\mathrm{P}$ on the phosphide start temperature and the effective solidus.

For those alloys with lower $\mathrm{P}$ contents $(<0.009 \mathrm{wt} \% \mathrm{P})$, the simulation is terminated at $0.1 \%$ liquid, before any phosphide can form. For higher $\mathrm{P}$ contents the simulation is extended to very low temperatures and phosphides are found (phosphides do not become stable until approximately $900^{\circ} \mathrm{C}$ ). It is noted that there are multiple solidus temperatures for a given $\mathrm{P}$ level in Figure 3, corresponding to the contributions of other alloying elements of different heats of materials.

Table 2. Effect of $P$ content on Scheil simulation results (letter suffix a, b, etc. indicate altered $P$ content)

\begin{tabular}{|c|c|c|c|}
\hline Alloy & P content (wt \%) & $\begin{array}{c}\text { Phosphide start } \\
\text { temperature }\left({ }^{\circ} \mathrm{C}\right)\end{array}$ & $\begin{array}{c}\text { Scheil effective solidus } \\
\left({ }^{\circ} \mathrm{C}\right)\end{array}$ \\
\hline 120138 & 0.002 & -- & 1141.4 \\
\hline $120138 \mathrm{a}$ & 0.006 & -- & 1068.7 \\
\hline $120138 \mathrm{~b}$ & 0.01 & 896.8 & 888.8 \\
\hline $120138 \mathrm{c}$ & 0.015 & 915.0 & 800.1 \\
\hline YT709 & 0.018 & 922.6 & 874.4 \\
\hline YT709a & 0.015 & 919.7 & 87.7 \\
\hline YT709b & 0.012 & 914.4 & 958.2 \\
\hline YT709c & 0.009 & -- & 1079.2 \\
\hline YT709d & 0.006 & -- & 1136.1 \\
\hline YT709e & 0.003 & -- & 1068.8 \\
\hline Average & 0.006 & -- & 946.9 \\
\hline Average & 0.009 & -- & 814.1 \\
\hline Average & 0.015 & 918.3 & \\
\hline
\end{tabular}

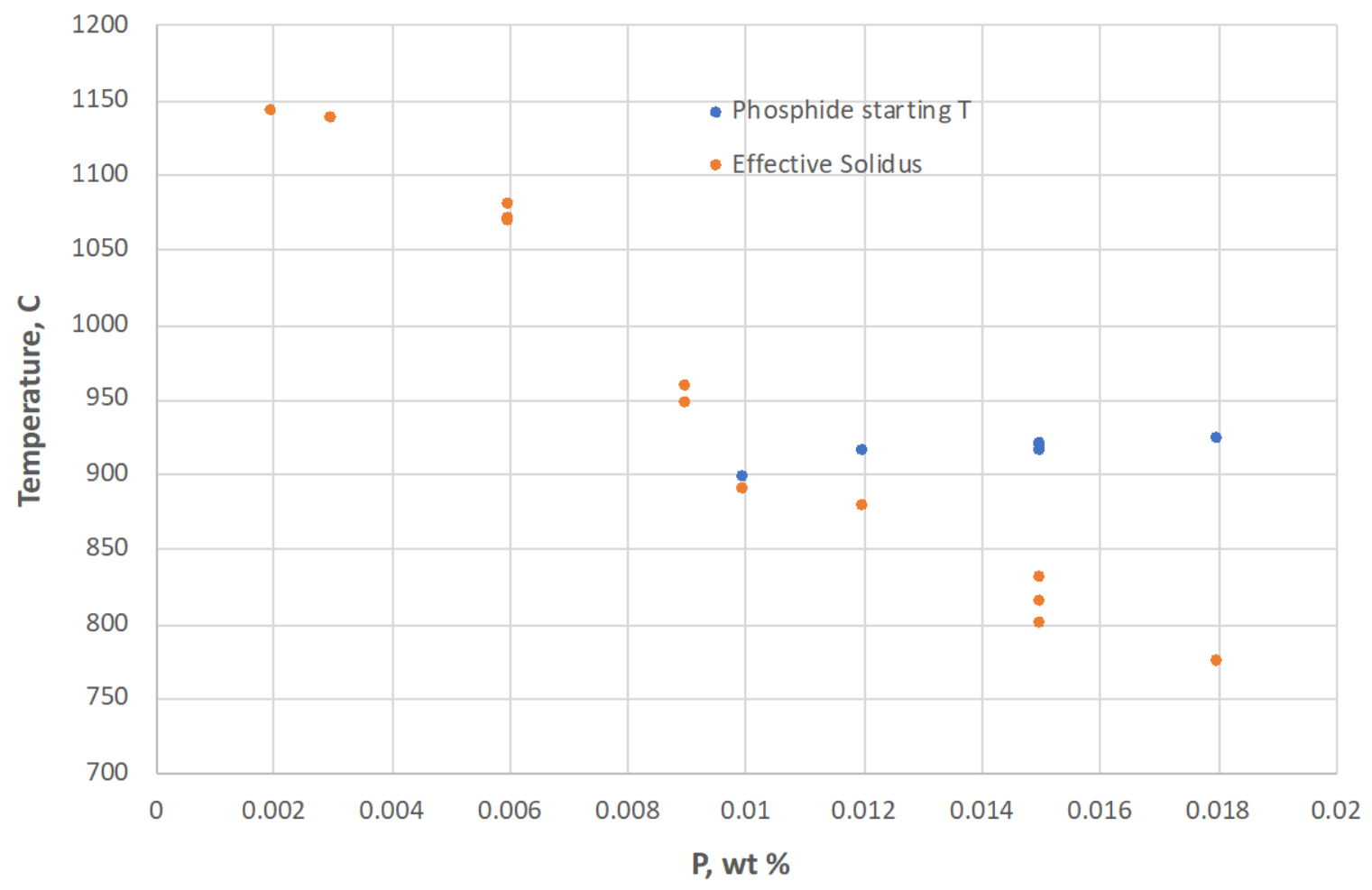

Figure 3 Effect of $P$ level on the phosphide start temperature, and the effective solidus. 
Plots of the distribution of $\mathrm{P}$ among the phases as a function of temperature are shown in Figure 4 and Figure 5. The vertical red, green, and purple lines are for reference and identify the 90, 95, and 99\% solid temperatures, respectively. The figures show that $P$ dissolves only in liquid (\#1), austenite (\#3), and phosphide (if present) (\#10 in Figure 5 only). In Figure 4, for the "average” alloy with 0.006 wt \% P, over $85 \%$ of all the P remains in the liquid until the simulation is terminated. In Figure 5, which is for alloy YT709 with 0.018 wt \% P, 85\% or more of the $\mathrm{P}$ remains in the liquid until $\mathrm{M}_{3} \mathrm{P}$ phosphide forms. The final "solidus" in Figure 5 is at a temperature significantly lower than the "solidus" in Figure 4 (774 vs. $1069^{\circ} \mathrm{C}$ ) with a lower P content. In addition, as shown in Figure 5, phosphide does not become stable until $f_{L I Q}<<1 \%$. For both levels of $\mathrm{P}, \mathrm{P}$ is segregated into the liquid until significantly less than $1 \%$ liquid remains, whether or not phosphide ultimately forms.

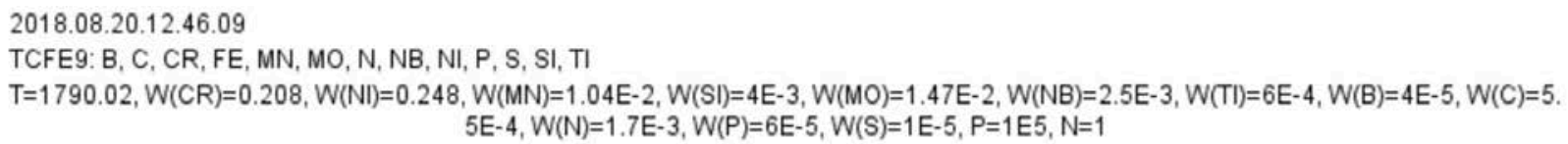
$5 E-4, W(N)=1,7 E-3, W(P)=6 E-5, W(S)=1 E-5, P=1 E 5, N=1$

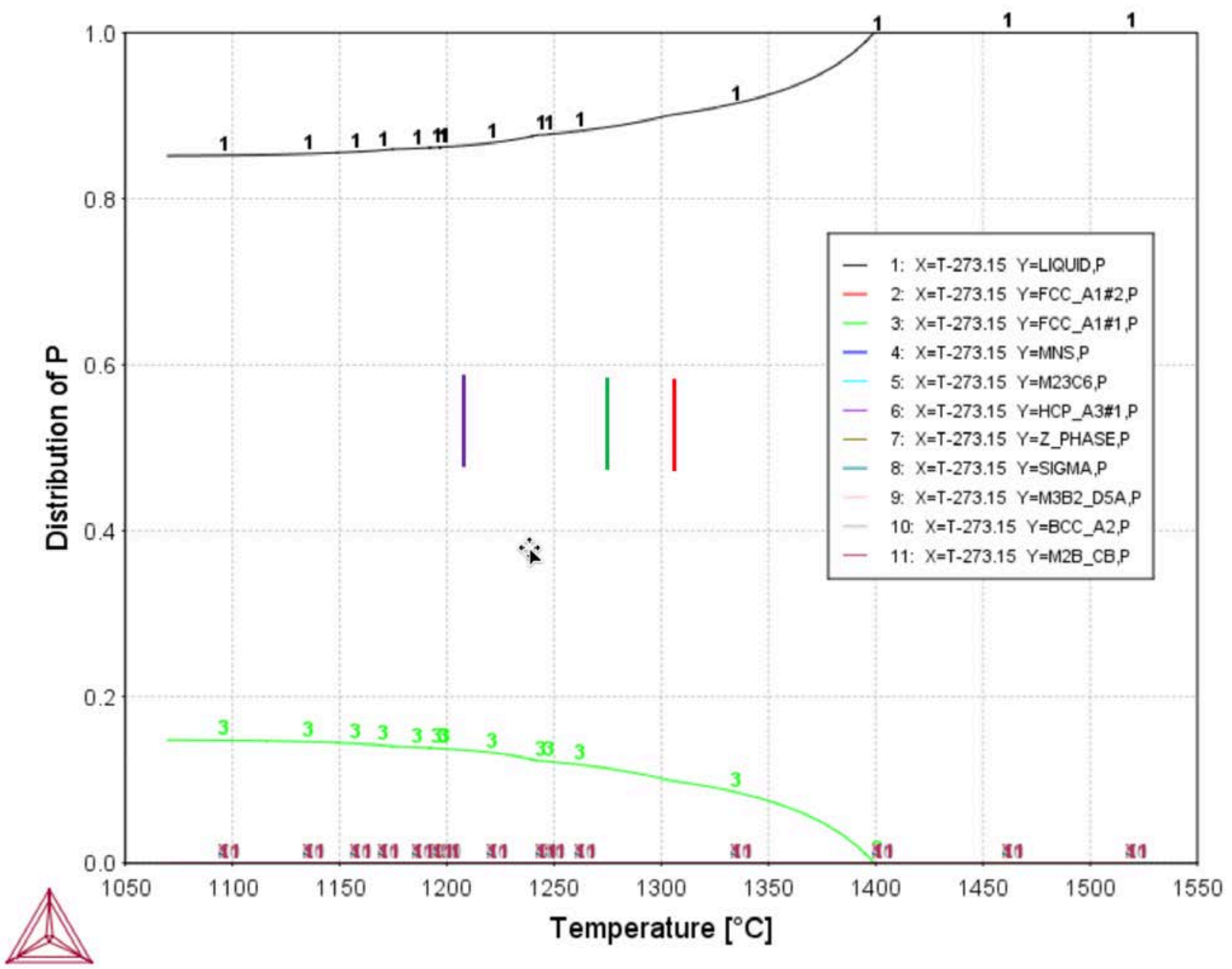

Figure 4. $P$ distribution among various phases as a function of temperature for Scheil simulationof "average" alloy with 0.006 wt \% P. Only 15\% of $P$ is dissolved in austenite (\#3) and remaining $P$ is in liquid (\#1). Red, green, and purple lines represent temperatures for 90,95 , and $99 \%$ solid, respectively. 


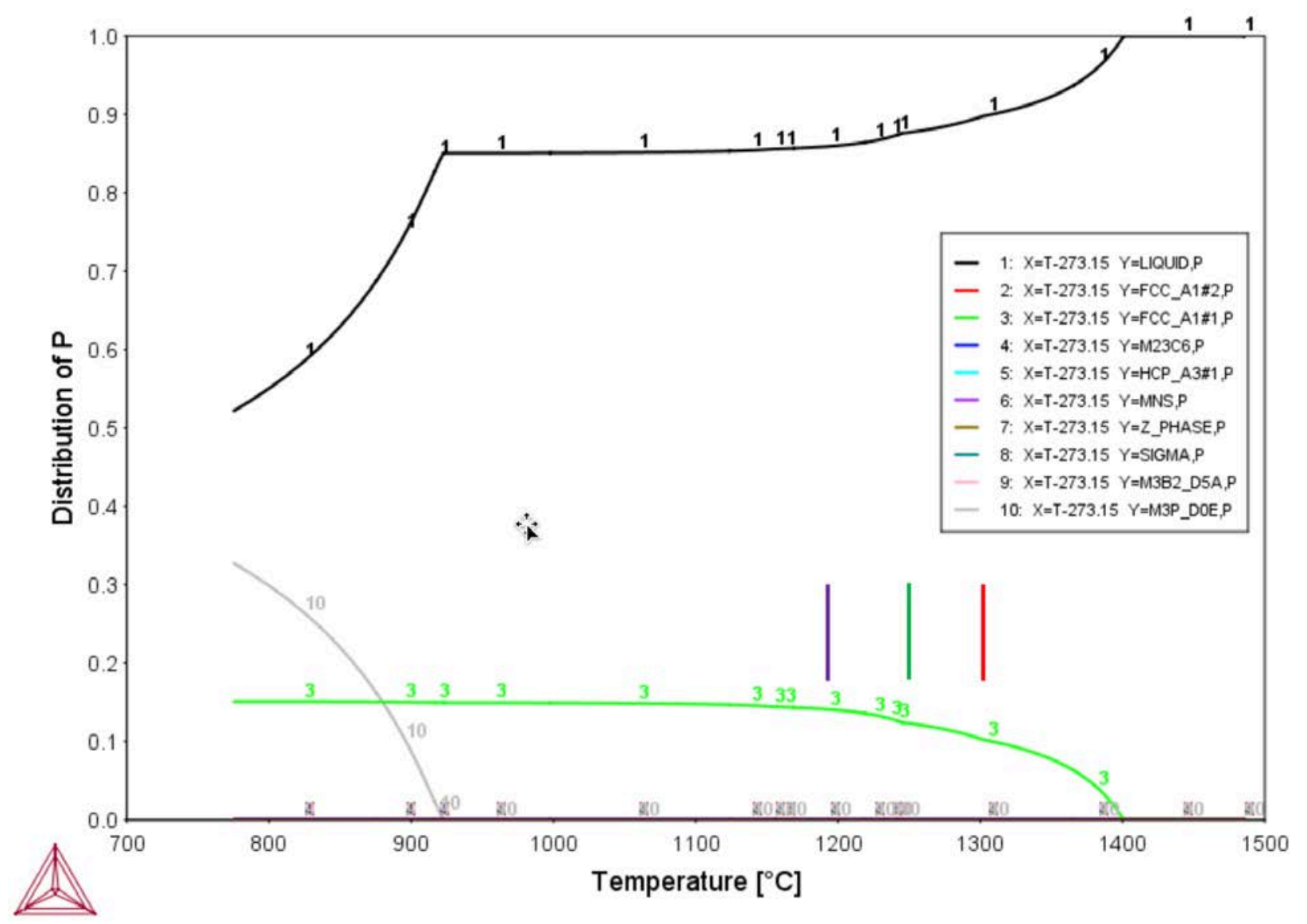

Figure 5. Plot of $P$ distribution among all phases present during Scheil simulation as a function of temperature for alloy YT709. P content of alloy is high ( $0.018 \mathrm{wt} \%)$ and $P$ remains primarily in liquid (\#1) until $\mathrm{M}_{3} \mathrm{P}(\# 10)$ becomes stable at low temperature. Red, green, and purple lines represent temperatures for 90, 95, and $99 \%$ solid, respectively.

Whether the simulation terminates before or after phosphide formation, the concentration of $\mathrm{P}$ in the remaining liquid can reach quite high levels. This is shown in Figure 6, where the liquid composition as a function of temperature for the "average" alloy (with only 0.006 wt \% P) is plotted. Even at such a "modest” overall P level, the remaining liquid can contain more than 5 wt \% P (\# 10 in Figure 6) before the simulation ends (note that wt fraction, not wt \%, is plotted in Figure 6). This is in stark contrast to the low concentrations of S and B found in the liquid (to be described later), even when the S or B levels are at the maximum permissible. This difference is a result of the fact that $\mathrm{S}$ and $\mathrm{B}$ are removed from the liquid by forming MnS or borides before the amount of remaining liquid drops to well under $1 \%$. At higher P levels in the alloy, the $\mathrm{P}$ content in the liquid can reach even higher levels of nearly $10 \mathrm{wt} \% \mathrm{P}$ as shown in Figure 7. Note that in Figure 7, the $\mathrm{P}$ concentration continues to rise even after phosphide formation $\left(918^{\circ} \mathrm{C}\right.$, Table 2$)$.

Additional simulations were made for a few other alloys to confirm the very strong influence of high $\mathrm{P}$ contents on the Scheil effective solidus. The results are shown in Figure 8 where the Scheil effective 
solidus is plotted versus the P content. Results for the alloys mentioned in Figure 2 as well as several additional alloys with varying compositions, are plotted. The trend of decreasing effective solidus with increasing $\mathrm{P}$ content is quite clear and consistent over the entire range of compositions. The scatter in the data relates to differences in concentrations of other elements. However, the P effect dominates over the impact of other elemental changes. For example, the data points at $0.015 \mathrm{wt} \% \mathrm{P}$ represent simulation results for four different alloys and the effect of variations in compositions is minimal compared to the large effect of $\mathrm{P}$ concentration. The same can be concluded from the data at $0.009 \mathrm{wt} \% \mathrm{P}$. where the scatter in the data includes data for the "average" alloy but with the B varying from 0.004 to $0.01 \mathrm{wt} \%$ or the S varying from 0.001 to 0.01 wt \% S. Thus, it is concluded that $P$ content has an overriding influence on the Scheil effective solidus, decreasing the solidus by hundreds of ${ }^{\circ} \mathrm{C}$ regardless of whether phosphide forms (wt \% $\mathrm{P} \geq 0.01$ ) or not (wt \% $\mathrm{P} \leq 0.009$ ) and these effects totally overshadow smaller effects from other alloying additions (such as B effects).

2018.08.20.13.00.04

TCFE9: B, C, CR, FE, MN, MO, N, NB, NI, P, S, SI, TI

$T=1790.02, W(C R)=0.208, W(N I)=0.248, W(M N)=1.04 E-2, W(S I)=4 E-3, W(M O)=1.47 E-2, W(N B)=2.5 E-3, W(T I)=6 E-4, W(B)=4 E-5, W(C)=5$. $5 \mathrm{E}-4, \mathrm{~W}(\mathrm{~N})=1.7 \mathrm{E}-3, \mathrm{~W}(\mathrm{P})=6 \mathrm{E}-5, \mathrm{~W}(\mathrm{~S})=1 \mathrm{E}-5, \mathrm{P}=1 \mathrm{E} 5, \mathrm{~N}=1$

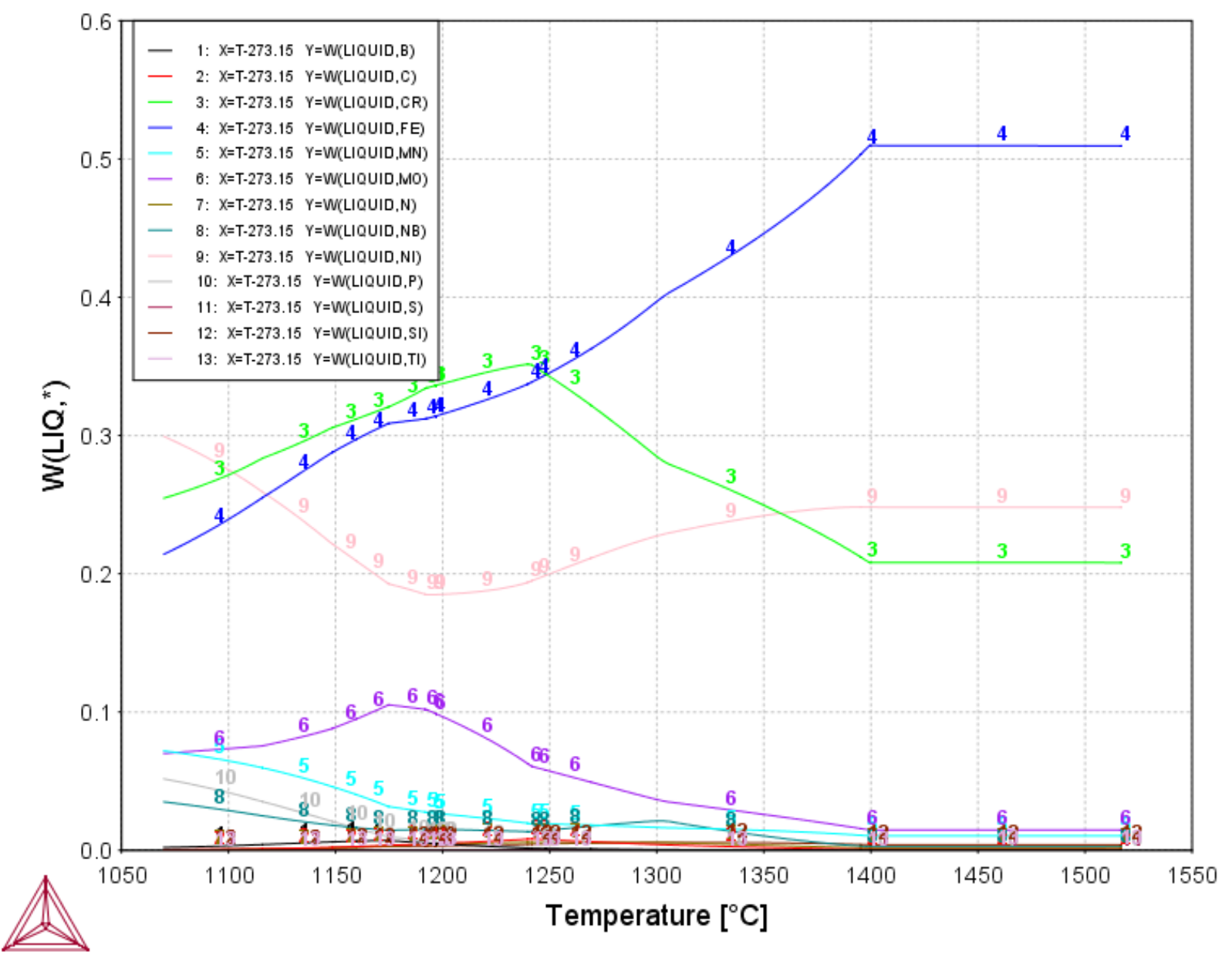

Figure 6. Liquid composition versus temperature for Scheil simulation of "average” alloy but with only 0.006 wt \% P. At low temperatures, the $P$ concentration (\#10) can reach $\approx 5 \mathrm{wt} \%$. Note that concentration is in wt fraction. 
2018.08.20.13.19.52

TCFE9: B, C, CR, FE, MN, MO, N, NB, NI, P, S, SI, TI

$T=1790.09, W(C R)=0.208, W(N I)=0.248, W(M N)=1.04 E-2, W(S I)=4 E-3, W(M O)=1.47 E-2, W(N B)=2.5 E-3, W(T I)=6 E-4, W(B)=4 E-5, W(C)=5$. $5 \mathrm{E}-4, \mathrm{~W}(\mathrm{~N})=1.7 \mathrm{E}-3, \mathrm{~W}(\mathrm{P})=1.5 \mathrm{E}-4, \mathrm{~W}(\mathrm{~S})=1 \mathrm{E}-5, \mathrm{P}=1 \mathrm{E} 5, \mathrm{~N}=1$

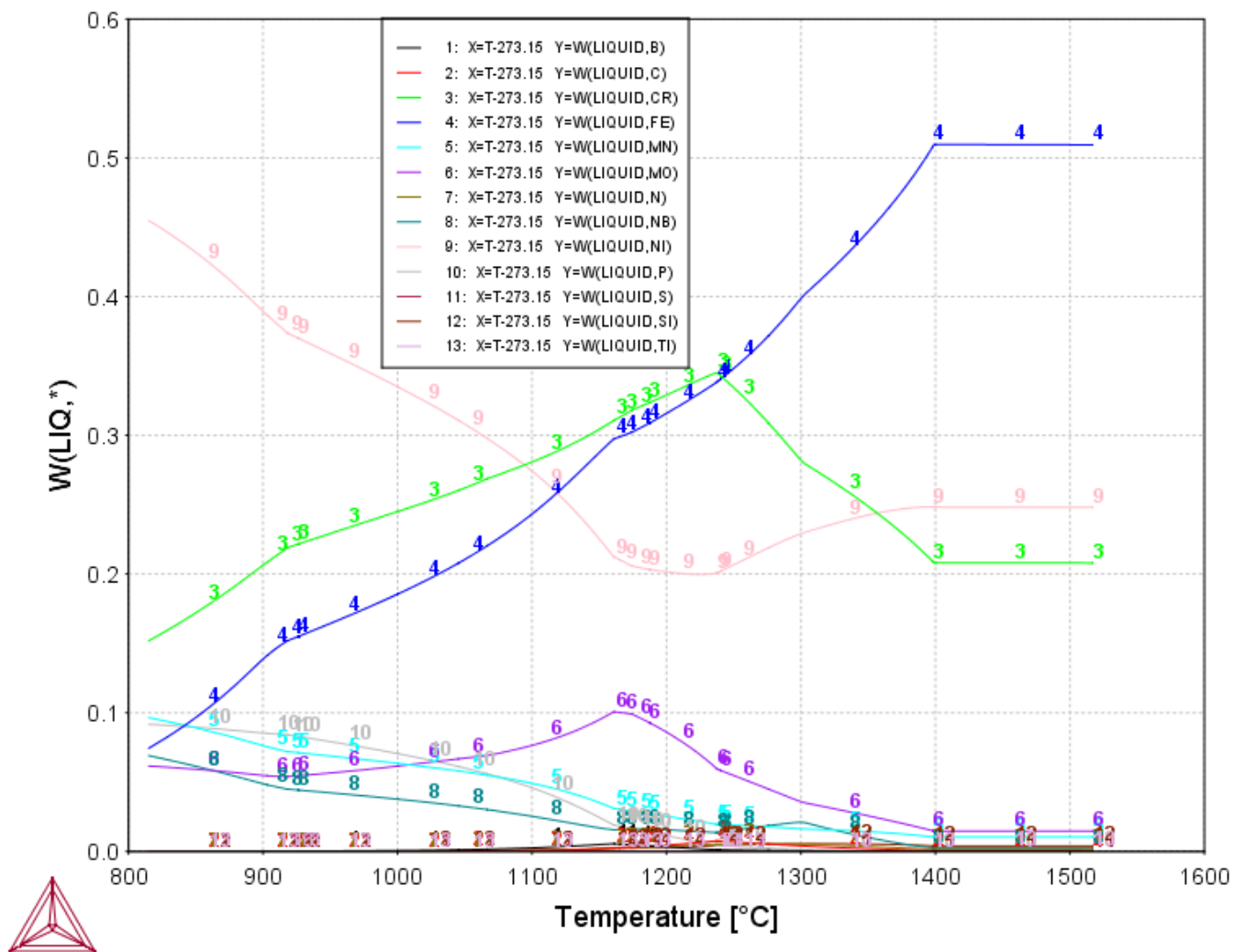

Figure 7. Liquid composition versus temperature for Scheil simulation of "average" alloy but with 0.015 wt $\%$ P. At low temperatures, the $P$ concentration (\#10) can reach nearly $10 \mathrm{wt} \%$. Concentration in wt fraction.

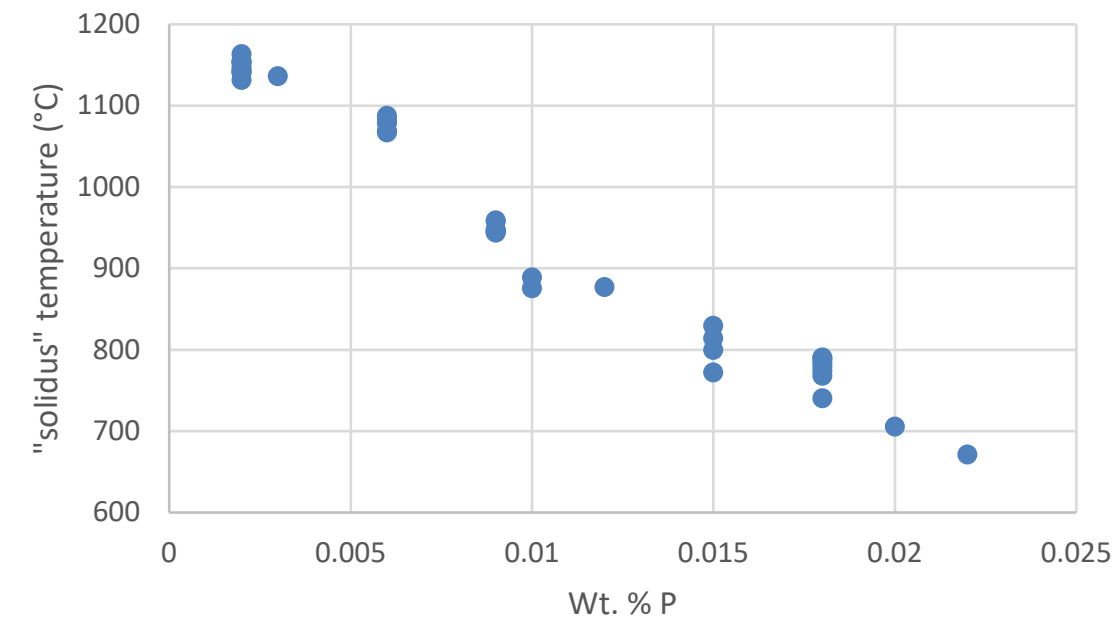

Figure 8. Scheil effective solidus temperatures vs. $P$ content for a wide range of alloys, including other compositions not presented in Table 1. 


\subsection{SULFUR EFFECTS}

In addition to phosphorus, sulfur is another impurity element that has profound influence on weld solidification cracking in stainless steels and nickel-based superalloys. While $\mathrm{S}$ was not explicitly identified to be associated with weld solidification cracking in the previous 709 welds, its potential effect should nevertheless be considered in developing solutions to mitigate weld solidification cracking in Alloy 709.

As noted earlier, MnS forms at relatively high temperatures under equilibrium conditions. Consequently, the solidus is not delayed until MnS becomes stable, even when the S content is high. The same general behavior is found under Scheil conditions. The temperature at which MnS forms under Scheil conditions is decreased somewhat compared to equilibrium conditions. For low S contents, MnS formation may be delayed by as much as $80^{\circ} \mathrm{C}$, but as the $\mathrm{S}$ content increases the decrease in formation temperature compared to equilibrium conditions decreases to $\approx 20^{\circ} \mathrm{C}$. Increasing the $\mathrm{S}$ content to the maximum allowed in the ASTM Alloy 709 specifications increases the formation temperature of MnS but has essentially no impact on the effective solidus. Mn content does not affect the formation temperature of MnS very much but reducing the Mn content raises the effective solidus slightly. The sulfide formation temperature and Scheil effective solidus (when $\mathrm{f}_{\mathrm{LIQ}}<0.001$ ) for many alloy compositions are shown in Table 3. The fact that the effective solidus does not change significantly with increasing $\mathrm{S}$ content and Scheil effective solidus is well below the formation temperature of MnS lead to the conclusion that the S content does not control the Scheil effective solidus which is an indicator of weld solidification cracking.

\begin{tabular}{|c|c|c|c|c|}
\hline \multicolumn{5}{|c|}{ Table 3. Effect of changes in S content on Scheil effective solidus temperature } \\
\hline Alloy (see Table 1) & S content (wt \%) & Mn content (wt \%) & $\begin{array}{c}\text { MnS start } \\
\text { temperature }\left({ }^{\circ} \mathrm{C}\right)\end{array}$ & $\begin{array}{c}\text { Scheil effective } \\
\text { solidus }\left({ }^{\circ} \mathrm{C}\right)\end{array}$ \\
\hline 120138 & 0.0005 & 0.97 & 1232.5 & 1141.4 \\
\hline 120138 & 0.01 & 0.97 & 1340.5 & 1140.9 \\
\hline 120138 & 0.01 & 0.5 & 1346.2 & 1154.0 \\
\hline 120138 & 0.01 & 0.1 & 1348.7 & 1163.6 \\
\hline YT709 & 0.0005 & 0.93 & 1219.0 & 774.4 \\
\hline YT709 & 0.01 & 0.93 & 1334.9 & 768.1 \\
\hline YT709d* & 0.0005 & 0.93 & 1233.4 & 1079.2 \\
\hline YT709d* & 0.01 & 0.93 & 1336.7 & 1079.3 \\
\hline Average & 0.001 & 1.04 & 1245.1 & 946.9 \\
\hline Average & 0.01 & 1.04 & 1337.7 & 948.0 \\
\hline * P content lowered from 0.018 to 0.006 wt \% & \\
\hline
\end{tabular}

The distribution of $S$ among the various phases present during the Scheil calculation reveals which phases $\mathrm{S}$ partitions to during the solidification process. This is shown in Figure 9 for the "average" composition (but only 0.006 wt \% P). Nearly all the S remains in the liquid (\#1 in Figure 9) until MnS (\#4 in Figure 9) forms. Once $\mathrm{MnS}$ precipitates, nearly all the $\mathrm{S}$ partitions to this phase during further solidification. To put this in the context of the overall solidification, the approximate temperatures for 90,95 , and $99 \%$ solid are superimposed in the figure as red, green and purple lines, respectively. This shows that nearly all the $\mathrm{S}$ remains in the liquid at 90 and $95 \%$ solid but by the time there is $99 \%$ solid, over $70 \%$ of all S is in MnS. The effect of $\mathrm{S}$ remaining in the liquid until less than $5 \%$ liquid remains can be also seen by examining the liquid composition as a function of temperature. Figure 10 shows the liquid composition as a function of temperature for the "average" composition but with the maximum S (0.01 wt \%) (note that the composition is plotted as wt fraction, not wt \%). The rejection of S into the liquid does not produce high S levels in the liquid (\#11 in the figure) at even the highest overall concentration of S. The S concentration in the liquid remains in the group of elements at the bottom of the figure, with the $S$ content $<<1 \%(0.01$ wt fraction). 
2018.08.20.12.50.39

TCFE9: B, C, CR, FE, MN, MO, N, NB, NI, P, S, SI, TI

$T=1790.02, W(C R)=0.208, W(N I)=0.248, W(M N)=1.04 E-2, W(S I)=4 E-3, W(M O)=1.47 E-2, W(N B)=2.5 E-3, W(T I)=6 E-4, W(B)=4 E-5, W(C)=5$. $5 \mathrm{E}-4, W(\mathrm{~N})=1.7 \mathrm{E}-3, \mathrm{~W}(\mathrm{P})=6 \mathrm{E}-5, \mathrm{~W}(\mathrm{~S})=1 \mathrm{E}-5, \mathrm{P}=1 \mathrm{E} 5, \mathrm{~N}=1$

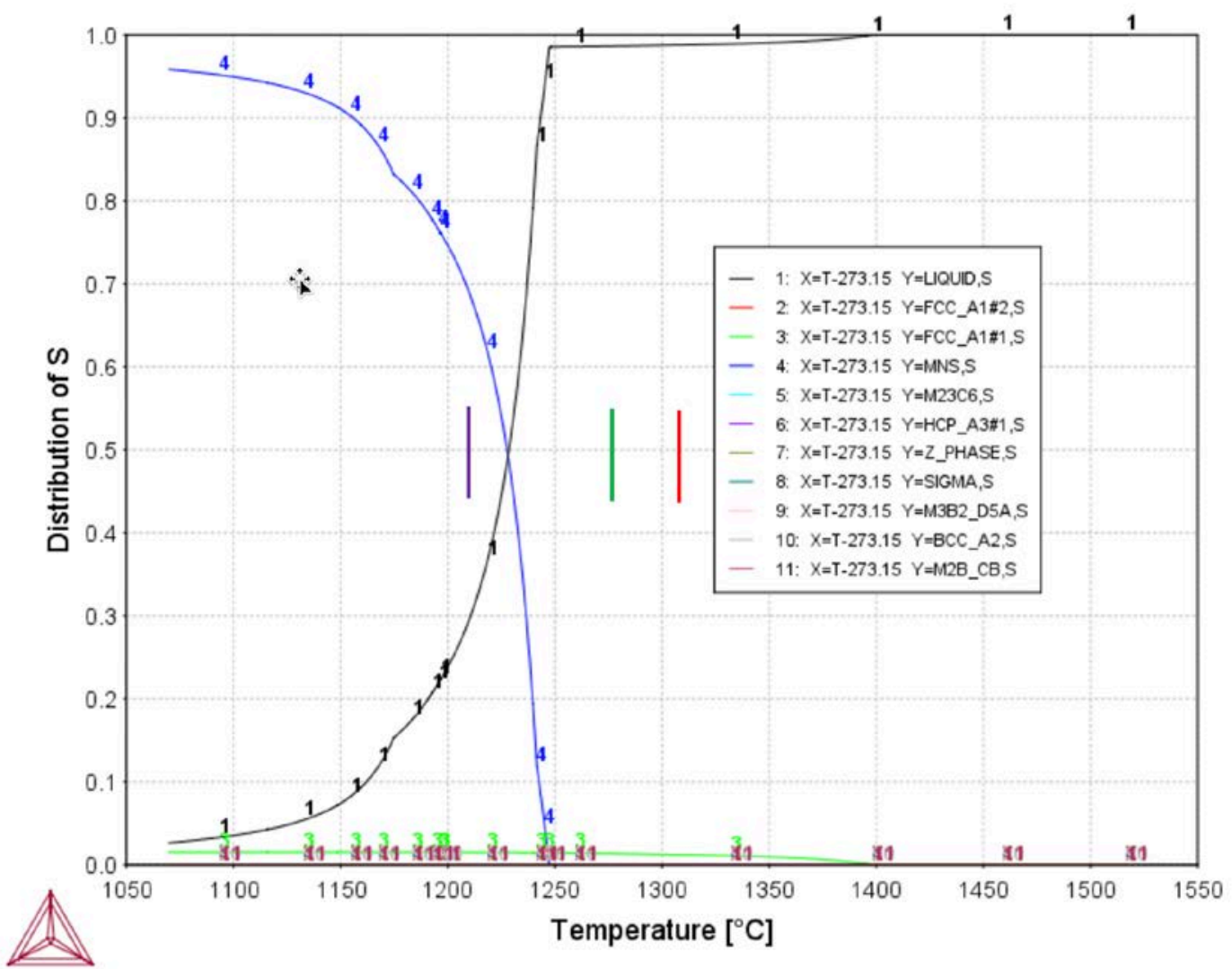

Figure 9. Plot of $S$ distribution among various phases during Scheil solidification of "average" alloy (but with only 0.006 wt \% P). S remains in liquid (\#1) until MnS (\#4) becomes stable. Red, green, and purple lines represent temperatures for 90,95 , and $99 \%$ solid, respectively. 


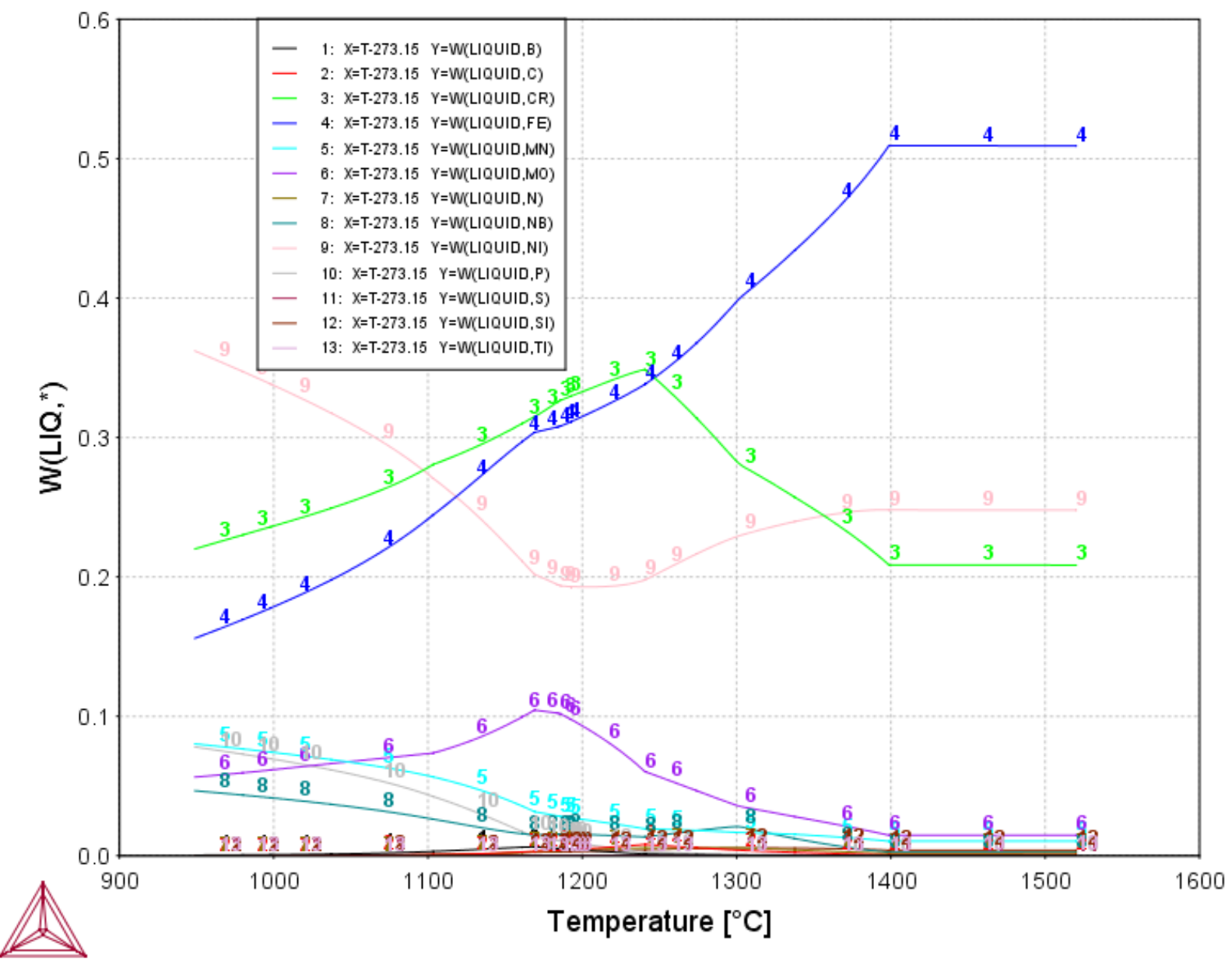

Figure 10. Liquid composition as a function of temperature for Scheil solidification of "average" alloy but with maximum allowed $S$ content $(0.01 \mathrm{wt} \%)$. S concentration remains well below $1 \mathrm{wt} \%$. Note that composition scale is in wt fraction (not wt \%). 


\subsection{BORON EFFECTS}

In equilibrium, B is rejected back into the liquid during solidification but as the temperature decreases the austenite solubility for boron also increases. At boron levels below the maximum allowed, austenite solubility of boron at lower temperatures is sufficient to absorb all the boron. However, at the maximum B levels ( 0.01 wt \%), solubility of $B$ in austenite is insufficient to account for all the $B$ and $\mathrm{M}_{2} \mathrm{~B}$ forms in equilibrium. Also, under equilibrium, if the B content is high enough to form the boride, then once the boride forms and acts as a sink for $\mathrm{B}$ in the liquid, then the liquid is no longer stable and the solidus is reached (see Table 4). At lower $B$ contents, when $\mathrm{M}_{2} \mathrm{~B}$ boride does not form in equilibrium, increasing $\mathrm{B}$ content leads to a moderate drop in the solidus.

The behavior under Scheil solidification conditions is somewhat different. First, a different boride $\left(\mathrm{M}_{3} \mathrm{~B}_{2}\right)$ forms, and it is found at all B levels in the alloy. Only at the highest B contents does $\mathrm{M}_{2} \mathrm{~B}$ form as well, at lower temperatures. Unlike the case in equilibrium, where the solidus is reached immediately upon $\mathrm{M}_{2} \mathrm{~B}$ formation at high $\mathrm{B}$ levels (within $1^{\circ} \mathrm{C}$ ), the Scheil effective solidus is further below the formation temperature of borides. The results of calculations for varying B contents are summarized in Table 4. The effective solidus behavior is different depending upon the $\mathrm{P}$ content. For alloys with low $\mathrm{P}$ content (alloy 120138, Table 1 and Table 4), the Scheil effective solidus is close to the formation temperature of $M_{3} B_{2}$ and the effective solidus decreases moderately as the B content increases. As the P content increases, the gap between the boride formation temperature and the effective solidus increases. The modest decrease in effective solidus with increasing B content is still observed in most cases, but this effect is marginal compared to the impact of higher P content (see next section). The exception is for the "average" alloy, where increasing the B content from 0.004 to 0.01 has basically no impact on the effective solidus. It is possible that the impact of increasing $\mathrm{B}$ on the effective solidus is greatest at low B levels and/or the drop in effective solidus with increasing B content is related to other constituents that are removed from the liquid as borides form.

\begin{tabular}{|c|c|c|c|c|c|}
\hline \multirow[t]{2}{*}{ Alloy } & \multirow{2}{*}{$\begin{array}{l}\text { B content } \\
\text { (wt \%) }\end{array}$} & \multicolumn{2}{|c|}{ Equilibrium conditions } & \multicolumn{2}{|c|}{ Scheil simulation } \\
\hline & & $\begin{array}{c}\text { Boride } \\
\text { formation } \mathrm{T}\end{array}$ & Solidus & $\begin{array}{c}\text { Boride } \\
\text { formation } \mathrm{T}\end{array}$ & $\begin{array}{c}\text { Effective } \\
\text { solidus }\end{array}$ \\
\hline 120138 & 0.001 & -- & 1318.5 & 1168.3 & 1154.2 \\
\hline 120138 & 0.0036 & -- & 1289.3 & 1182.4 & 1141.4 \\
\hline 120138 & 0.01 & 1213.5 & 1213.5 & 1186.7 & 1131.8 \\
\hline YT709 & 0.001 & -- & 1302.9 & 1124.3 & 784.8 \\
\hline YT709 & 0.003 & -- & 1281.9 & 1155.2 & 774.4 \\
\hline YT709 & 0.01 & 1207.2 & 1207.2 & 1178.4 & 740.3 \\
\hline YT709d* & 0.001 & -- & 1312.5 & 1153.9 & 1087.9 \\
\hline YT709d* & 0.003 & -- & 1290.9 & 1174.5 & 1079.2 \\
\hline YT709d* & 0.01 & 1211.5 & 1211.5 & 1189.0 & 1067.0 \\
\hline Average & 0.004 & -- & 1278.0 & 1169.3 & 946.9 \\
\hline Average & 0.01 & 1211.4 & 1211.3 & 1181.8 & 944.1 \\
\hline
\end{tabular}

A plot of the distribution of $\mathrm{B}$ among the various phases as a function of temperature during Scheil solidification is shown in Figure 11 for the "average" composition (but only $0.006 \mathrm{wt} \% \mathrm{P}$ ). The behavior is very similar to that found for $\mathrm{S}$ (see Figure 9). B remains partitioned to the liquid until the boride forms and then B partitions primarily to the $\mathrm{M}_{3} \mathrm{~B}_{2}$ boride (\#9 in Figure 11). Some B is present in austenite (\#3, Figure 11). At the latter stages of solidification, the $M_{2} B$ boride forms (\#11, Figure 11) and absorbs some of the B in the remaining liquid. As in Figure 9, the approximate temperatures for 90, 95, and 99\% solid 
are superimposed on Figure 11. Since the boride formation temperature is lower than that for MnS, the B remains in the liquid until approximately $99 \%$ solid is present. The consequence of the rejection of B into liquid during solidification is shown in Figure 12, where the liquid composition as a function of temperature is shown for the "average" alloy composition but with the maximum allowed B content (0.01 wt \%). Note, again, that the composition is plotted as wt fraction and not wt \%. As was the case for $\mathrm{S}$, the rejection of B into the liquid until less than $1 \%$ liquid remains does not produce high concentrations of B in the liquid. The B concentration (\#1 in Figure 12) is among the group of elements that comprise $<<1 \%$ of the liquid. In fact, the general composition of liquid versus temperature for the "average" alloy with maximum B (Figure 12) looks very much like the plot for the "average” alloy with maximum S (Figure $10)$.

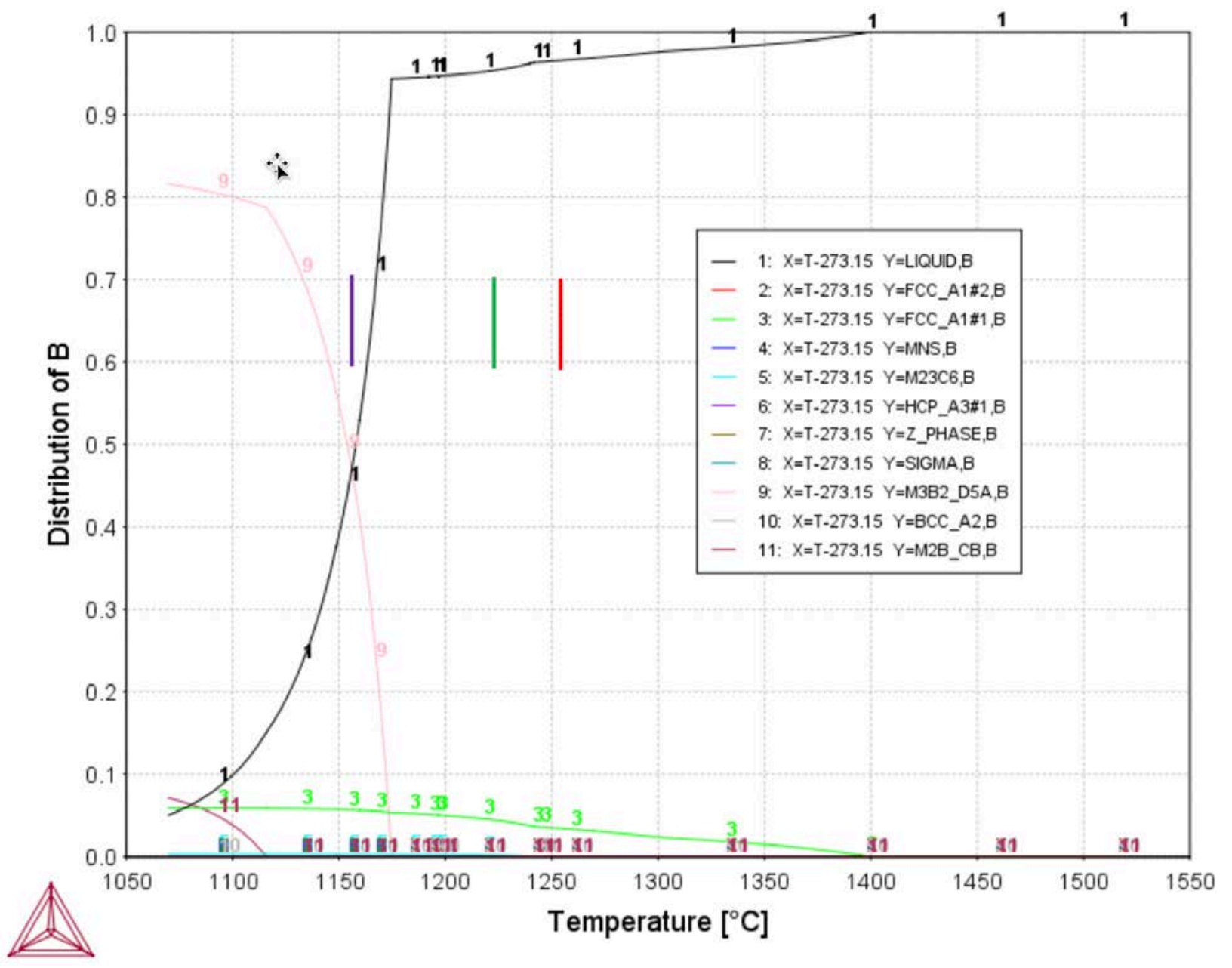

Figure 11. B distribution among the various phases as a function of temperature for the Scheil simulation of "average" alloy but with only 0.006 wt \% P. B remains mostly in liquid (\#1) until $\mathbf{M}_{3} B_{2}$ (\#9) becomes stable.

Red, green, and purple lines represent temperatures for 90,95 , and $99 \%$ solid, respectively. 


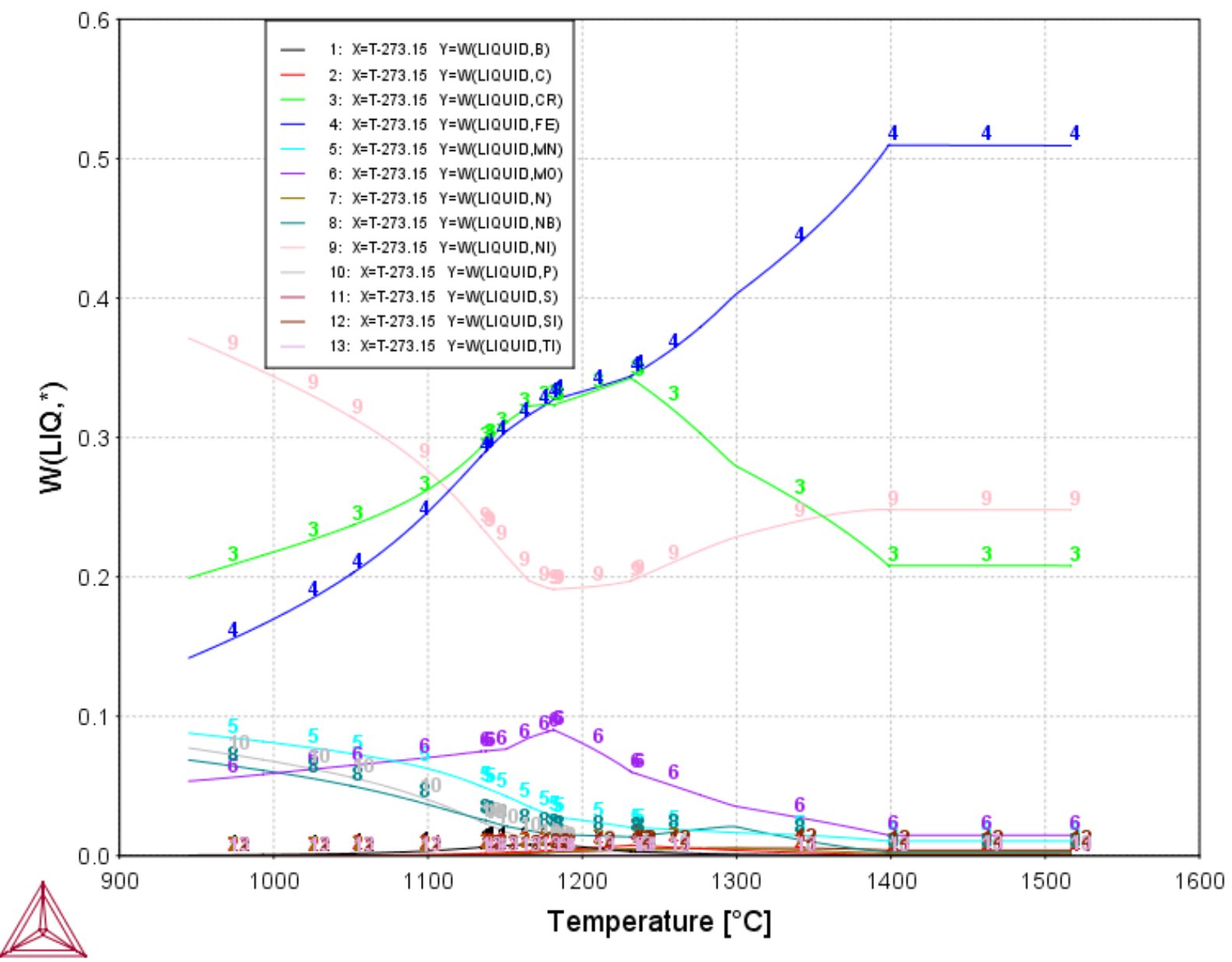

Figure 12. Liquid composition versus temperature for Scheil simulation of "average" alloy but with maximum B (0.01 wt \%). Even though B partitions to liquid until boride formation, the B concentration (\#1) remains low. Note that concentration is in wt fraction, not wt \%. 


\subsection{EFFECTS OF OTHER ALLOYING ELEMENTS}

Detailed Scheil simulations to investigate the impact of other alloying elements on the solidification behavior were not done. However, two factors indicate that the effect of other alloying elements is not expected to be large. First, as shown in Figure 8, the scatter in the data is rather small in comparison to the large impact of $\mathrm{P}$ concentration. Thus, for example, the data at $0.015 \mathrm{wt} \% \mathrm{P}$ represents the simulation results for four different alloys, with different levels of all elements except $\mathrm{P}$, and yet the scatter is less than the impact of changing the P level by $0.002 \mathrm{wt} \%$. Another example can be seen at $0.009 \mathrm{wt} \% \mathrm{P}$, where the scatter includes changes in B and S from minimal values to the maximum allowed (0.01 wt \%) and yet the effective solidus scatter is equivalent to changes of roughly $\pm 0.002 \mathrm{wt} \% \mathrm{P}$.

Another key factor is the segregation behavior of other elements and how that compares to the behavior for S, B, and P. In Figure 13 to Figure 21, the distribution of Cr, Ni, Mn, Si, Mo, Nb, Ti, C, and N among the various phases are plotted versus temperature, respectively. The base alloy in all of these plots is the "average" alloy with 0.006 wt \% P. The plots show a very similar pattern, and one that is basically different than that found for S, B, and P. For Cr, Ni, Mn, Si, and Mo (Figure 13 - Figure 17), all or nearly all of the elements partition to austenite and not to the liquid (some Mo partitions to $\mathrm{M}_{23} \mathrm{C}_{6}$ when that carbide becomes stable). Some Nb partitions to austenite (\#3, Figure 18) but most goes into the Nb carbonitride (\#2, Figure 18) which is stable at high temperatures $\left(\approx 1300^{\circ} \mathrm{C}\right)$. Ti partitions to the TiN phase (\#2, Figure 19) and this phase forms at the highest temperatures $\left(\approx 1500^{\circ} \mathrm{C}\right)$. C partitions primarily to 3 phases, austenite (\#3, Figure 20), Nb carbo-nitride (\#2, Figure 20), and $\mathrm{M}_{23} \mathrm{C}_{6}$ carbide (\#5, Figure 20). All of these phases are stable and form at high temperatures of $1300^{\circ} \mathrm{C}$ or higher. Finally, $\mathrm{N}$ partitions to 3 phases, TiN (\#2, Figure 21), austenite (\#3, Figure 21), and Nb carbo-nitride (\#2, Figure 21, below $\approx$ $\left.1300^{\circ} \mathrm{C}\right)$. As was the case for carbon, all of these phases are stable at high temperatures $\left(1300^{\circ} \mathrm{C}\right.$ and higher). Thus, in contrast to S, B, and P, none of these elements remains in the liquid until latter stages of solidification. They are more or less completely dissolved in solid phases at high temperatures. One can also look at the distribution of all of these elements relative to the amount of solid present, given by the red, green, and purple lines in Figure 13 to Figure 21 (90, 95, and 99\% solid, respectively). For Cr, Ni, $\mathrm{Mn}, \mathrm{Si}$, and $\mathrm{Ti}$, less than roughly $15 \%$ of each element remains in the liquid at the point where there is $90 \%$ solid. For these elements, $<10 \%$ of each of them is present in the liquid when there is $95 \%$ solid. For the other elements (Mo, Nb, C, N), they are quickly removed from the liquid once the $\mathrm{M}_{23} \mathrm{C}_{6}$ or $\mathrm{Nb}(\mathrm{C}, \mathrm{N}$ ) phases become stable so that by the time there is $95 \%$ solid, $50 \%$ or more of these elements are removed from the liquid and at the temperature where there is $99 \%$ solid, more than $90 \%$ of these elements are present in the solid and less than $10 \%$ of each of these elements remains in the liquid. 
$T=1790.02, W(C R)=0.208, W(N I)=0.248, W(M N)=1.04 E-2, W(S I)=4 E-3, W(M O)=1.47 E-2, W(N B)=2.5 E-3, W(T I)=6 E-4, W(B)=4 E-5, W(C)=5$. $5 E-4, W(N)=1.7 E-3, W(P)=6 E-5, W(S)=1 E-5, P=1 E 5, N=1$

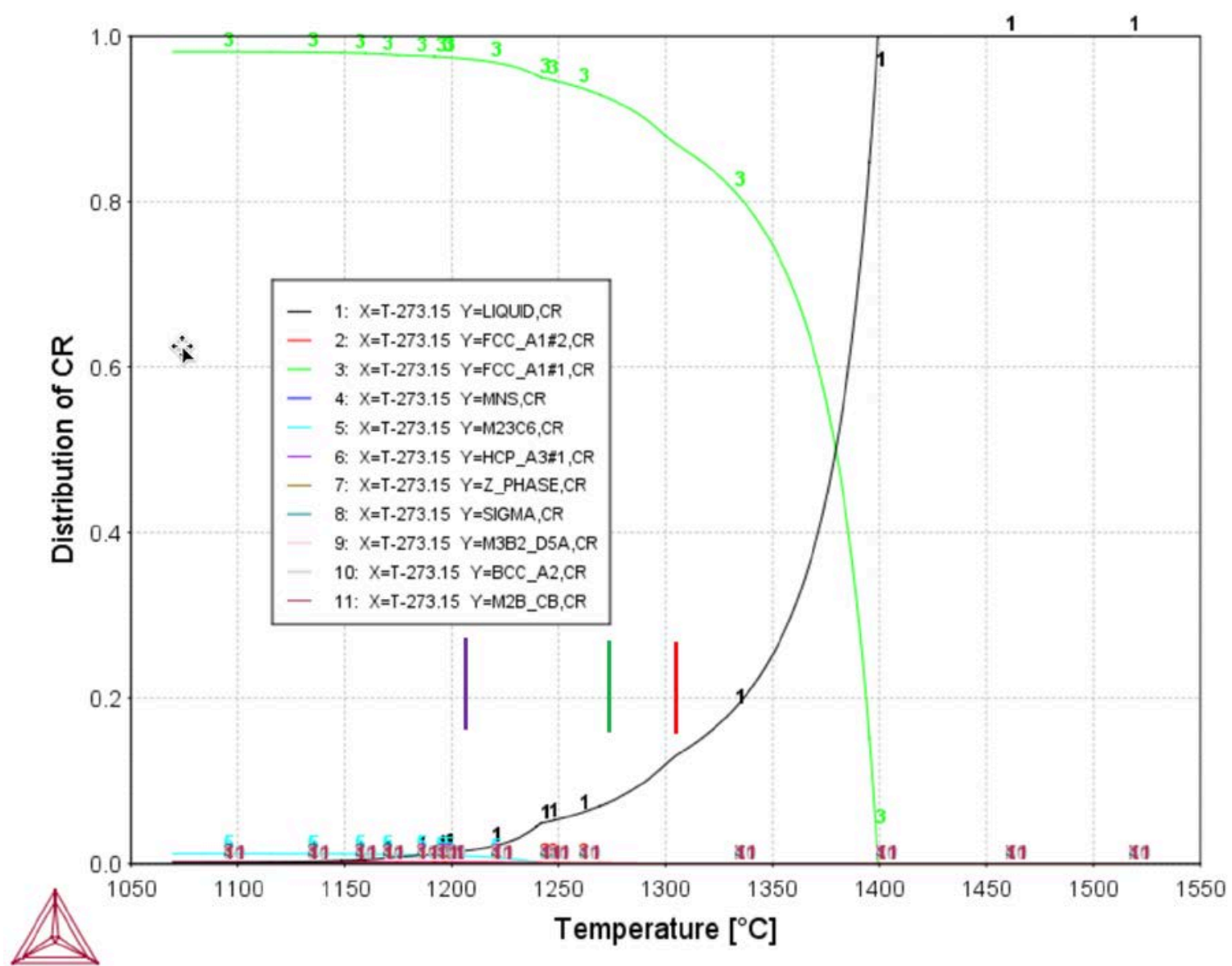

Figure 13. Distribution of $\mathrm{Cr}$ among the various phases as a function of temperature for Scheil simulation of "average" alloy with 0.006 wt \% P. Red, green, and purple lines represent temperatures for 90, 95, and 99\% solid, respectively. 
$T=1790.02, W(C R)=0.208, W(N I)=0.248, W(M N)=1.04 E-2, W(S I)=4 E-3, W(M O)=1.47 E-2, W(N B)=2.5 E-3, W(T I)=6 E-4, W(B)=4 E-5, W(C)=5$. $5 E-4, W(N)=1.7 E-3, W(P)=6 E-5, W(S)=1 E-5, P=1 E 5, N=1$

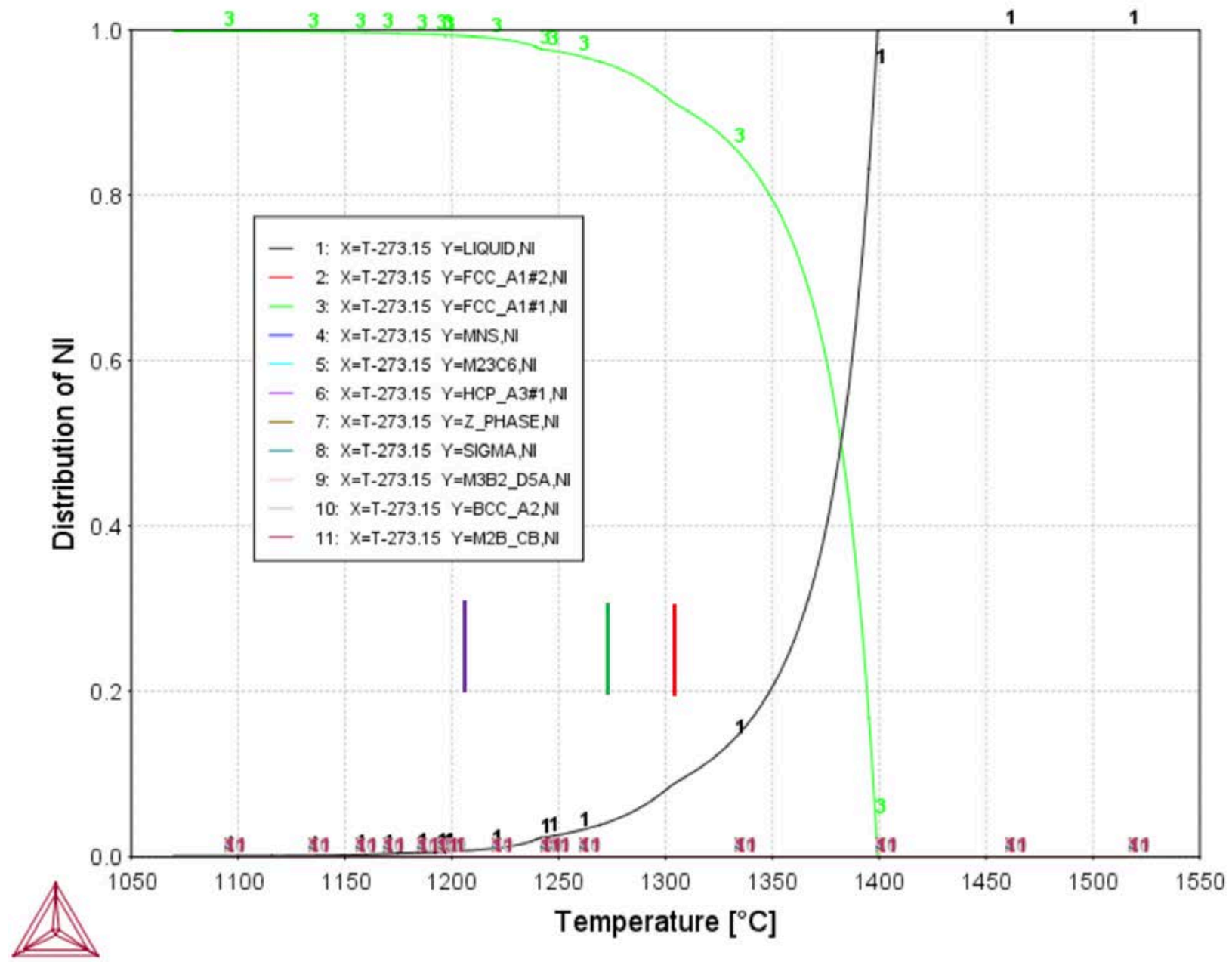

Figure 14. Distribution of Ni among the various phases as a function of temperature for Scheil simulation of "average" alloy with 0.006 wt \% P. Red, green, and purple lines represent temperatures for 90, 95, and 99\% solid, respectively. 
2018.08.20.12.08.23

TCFE9: B, C, CR, FE, MN, MO, N, NB, NI, P, S, SI, TI

$T=1790.02, W(C R)=0.208, W(N I)=0.248, W(M N)=1.04 E-2, W(S I)=4 E-3, W(M O)=1.47 E-2, W(N B)=2.5 E-3, W(T I)=6 E-4, W(B)=4 E-5, W(C)=5$. $5 E-4, W(N)=1.7 E-3, W(P)=6 E-5, W(S)=1 E-5, P=1 E 5, N=1$

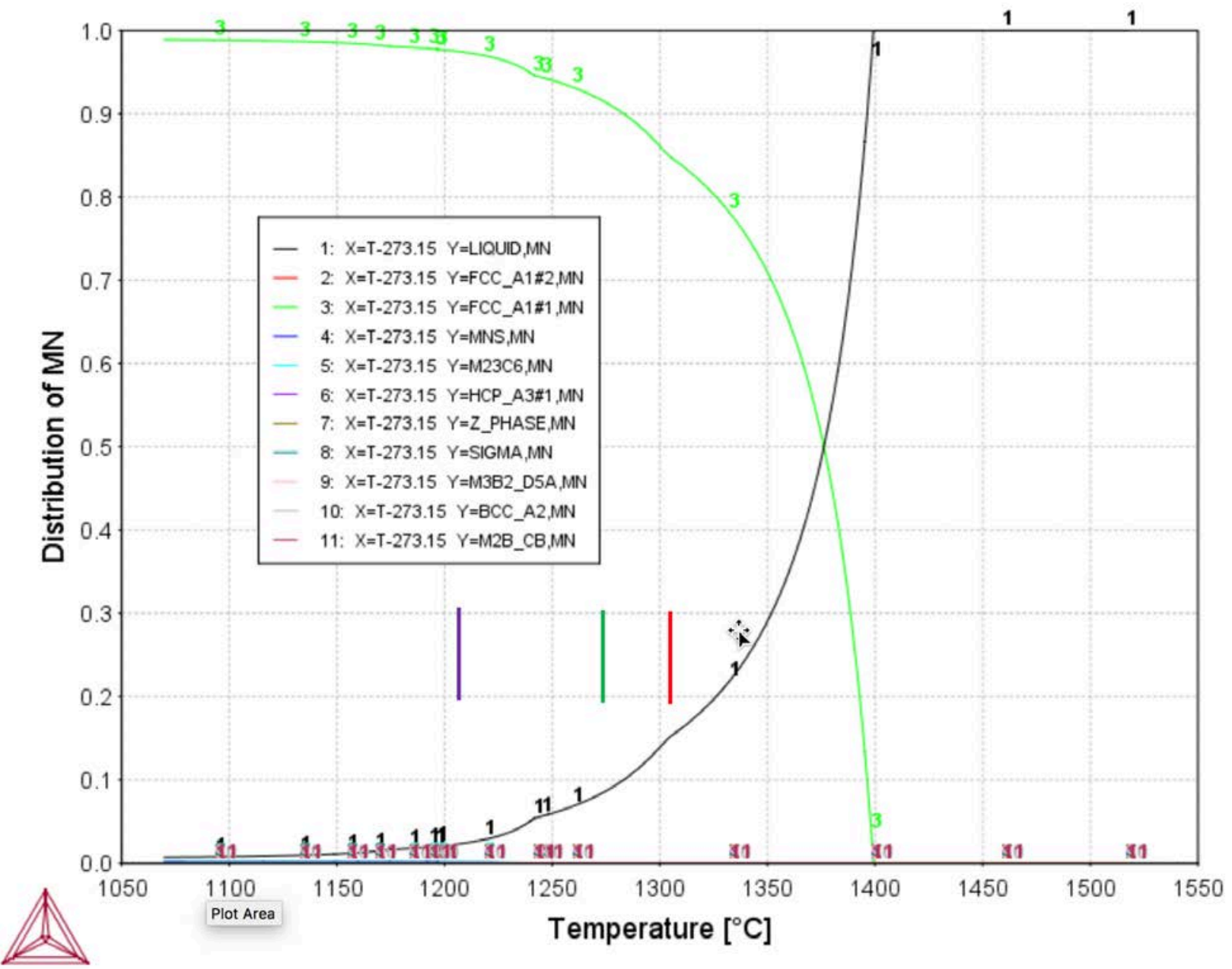

Figure 15. Distribution of Mn among the various phases as a function of temperature for Scheil simulation of "average" alloy with 0.006 wt \% P. Red, green, and purple lines represent temperatures for 90, 95, and 99\% solid, respectively. 
$T=1790.02, W(C R)=0.208, W(N I)=0.248, W(M N)=1.04 E-2, W(S I)=4 E-3, W(M O)=1.47 E-2, W(N B)=2.5 E-3, W(T I)=6 E-4, W(B)=4 E-5, W(C)=5$. $5 E-4, W(N)=1.7 E-3, W(P)=6 E-5, W(S)=1 E-5, P=1 E 5, N=1$

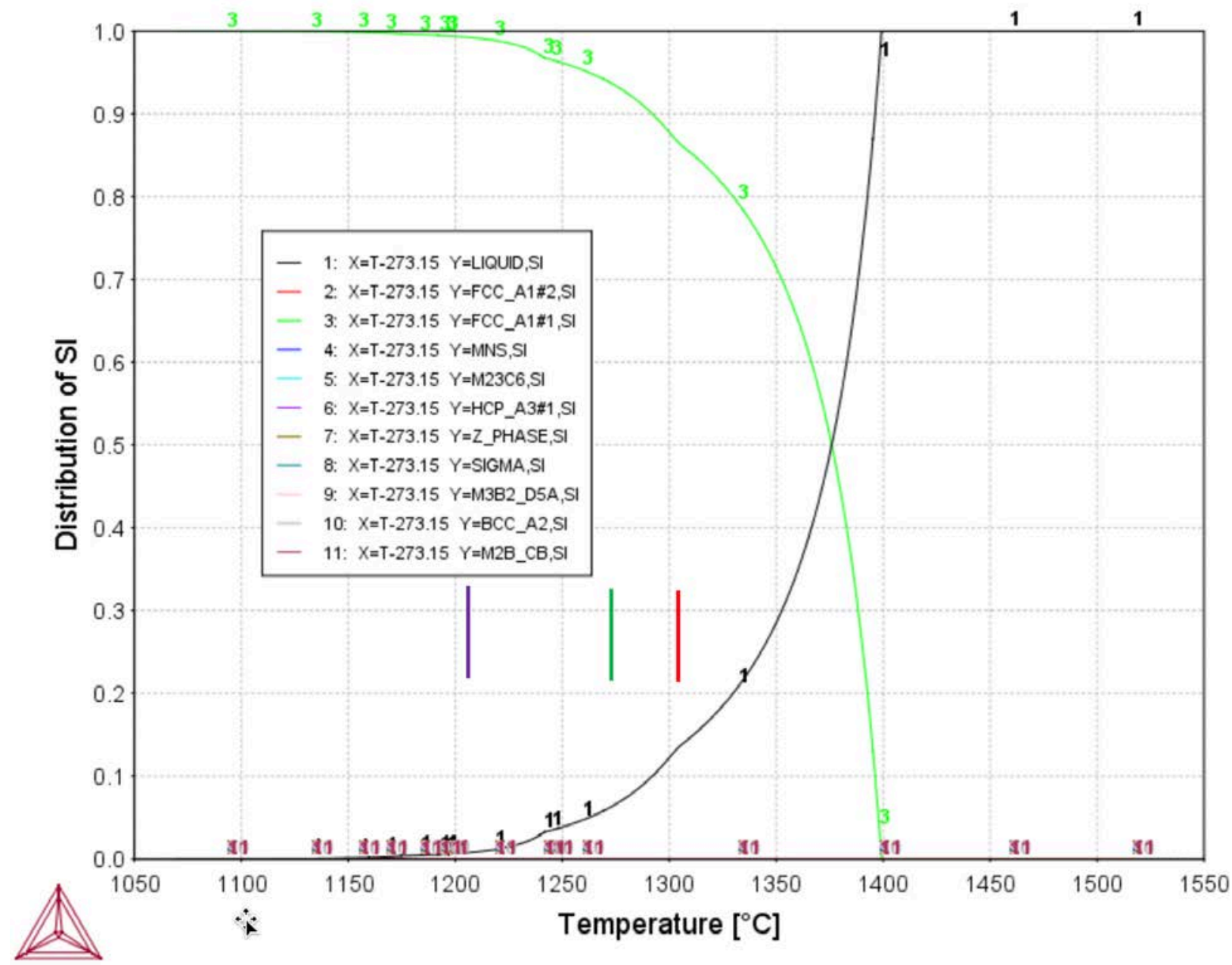

Figure 16. Distribution of Si among the various phases as a function of temperature for Scheil simulation of "average" alloy with 0.006 wt \% P. Red, green, and purple lines represent temperatures for 90, 95, and 99\% solid, respectively. 
$T=1790.02, W(C R)=0.208, W(N I)=0.248, W(M N)=1.04 E-2, W(S I)=4 E-3, W(M O)=1.47 E-2, W(N B)=2.5 E-3, W(T I)=6 E-4, W(B)=4 E-5, W(C)=5$. $5 E-4, W(N)=1.7 E-3, W(P)=6 E-5, W(S)=1 E-5, P=1 E 5, N=1$

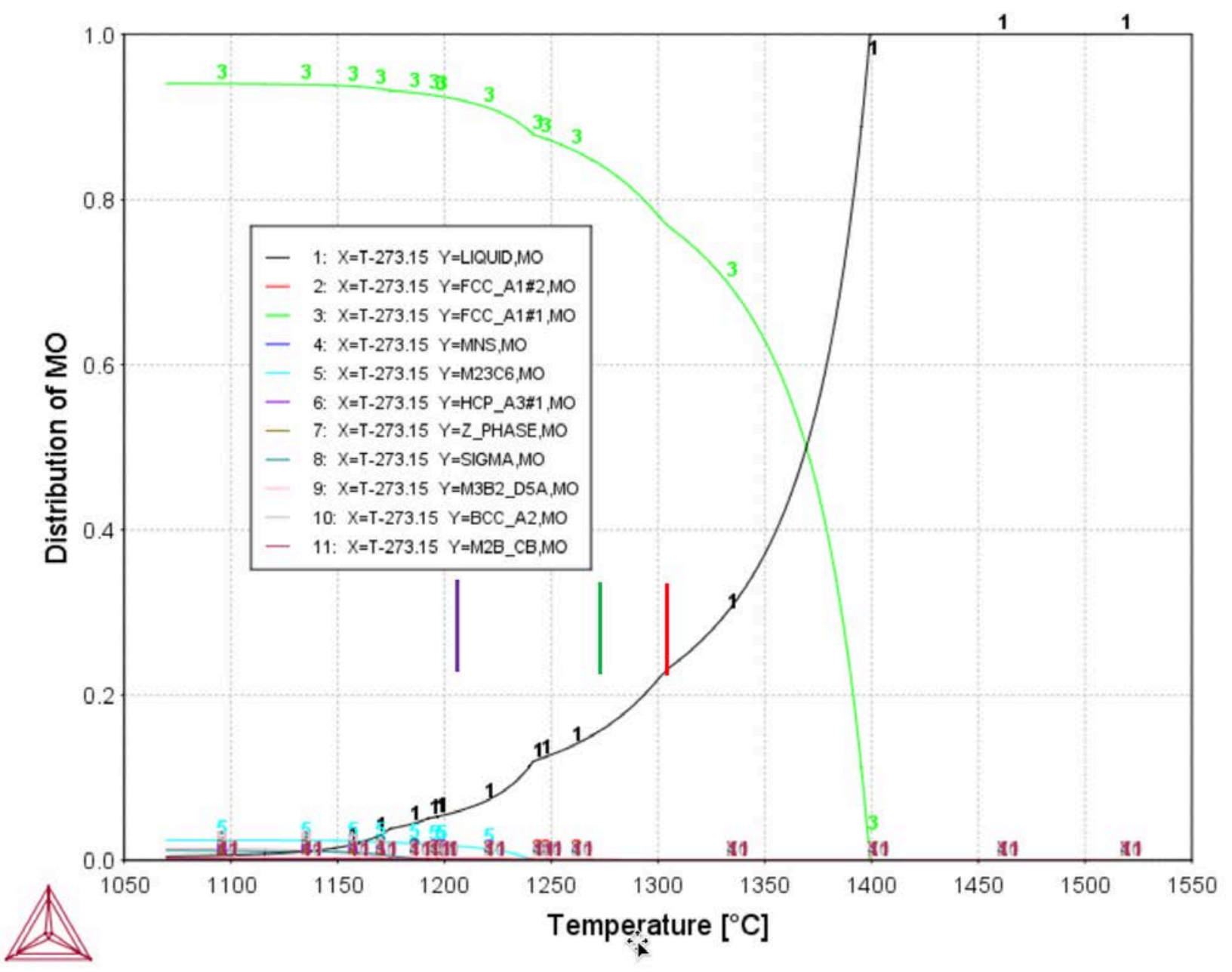

Figure 17. Distribution of Mo among the various phases as a function of temperature for Scheil simulation of "average" alloy with 0.006 wt \% P. Red, green, and purple lines represent temperatures for 90, 95, and 99\% solid, respectively. 
$T=1790.02, W(C R)=0.208, W(N I)=0.248, W(M N)=1.04 E-2, W(S I)=4 E-3, W(M O)=1.47 E-2, W(N B)=2.5 E-3, W(T I)=6 E-4, W(B)=4 E-5, W(C)=5$. $5 E-4, W(N)=1.7 E-3, W(P)=6 E-5, W(S)=1 E-5, P=1 E 5, N=1$

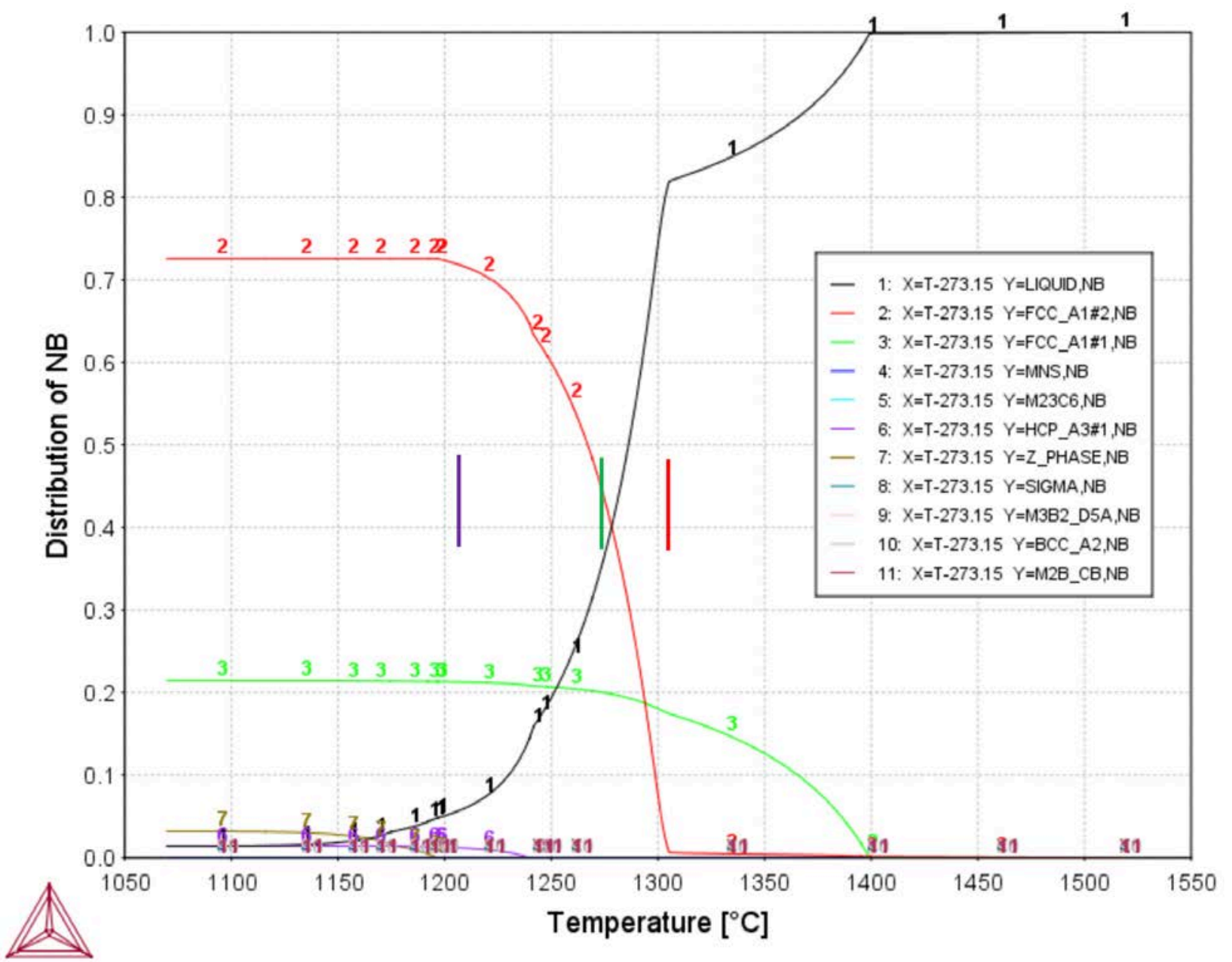

Figure 18. Distribution of $\mathbf{N b}$ among the various phases as a function of temperature for Scheil simulation of "average" alloy with 0.006 wt \% P. Red, green, and purple lines represent temperatures for 90, 95, and 99\% solid, respectively. 
2018.08.20.12.27.43

TCFE9: B, C, CR, FE, MN, MO, N, NB, NI, P, S, SI, TI

$T=1790.02, W(C R)=0.208, W(N I)=0.248, W(M N)=1.04 E-2, W(S I)=4 E-3, W(M O)=1.47 E-2, W(N B)=2.5 E-3, W(T I)=6 E-4, W(B)=4 E-5, W(C)=5$. $5 E-4, W(N)=1.7 E-3, W(P)=6 E-5, W(S)=1 E-5, P=1 E 5, N=1$

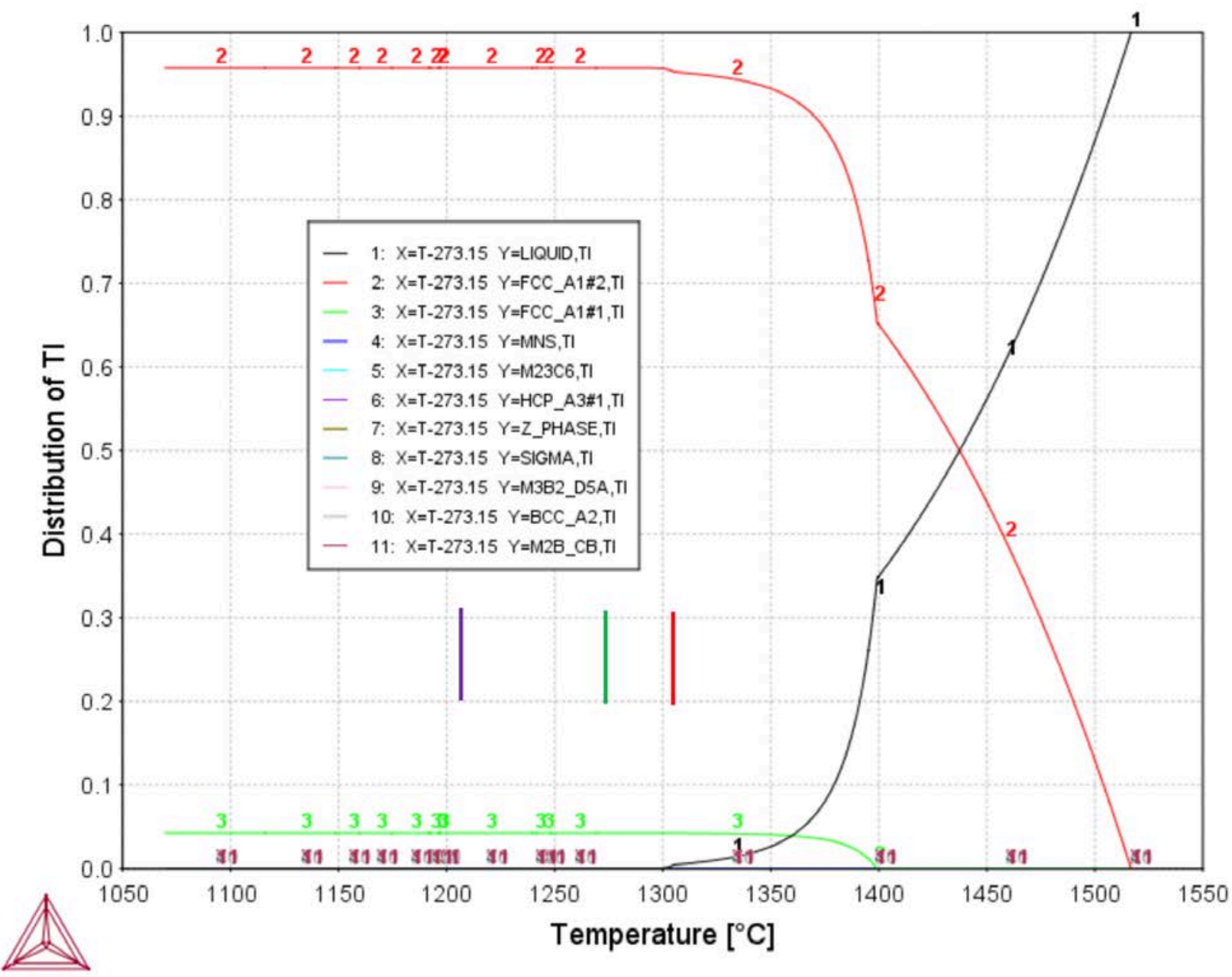

Figure 19. Distribution of Ti among the various phases as a function of temperature for Scheil simulation of "average" alloy with 0.006 wt \% P. Red, green, and purple lines represent temperatures for 90, 95, and 99\% solid, respectively. 
2018.08.20.12.36.54

TCFE9: B, C, CR, FE, MN, MO, N, NB, NI, P, S, SI, TI

$T=1790.02, W(C R)=0.208, W(N I)=0.248, W(M N)=1.04 E-2, W(S I)=4 E-3, W(M O)=1.47 E-2, W(N B)=2.5 E-3, W(T I)=6 E-4, W(B)=4 E-5, W(C)=5$. $5 E-4, W(N)=1.7 E-3, W(P)=6 E-5, W(S)=1 E-5, P=1 E 5, N=1$

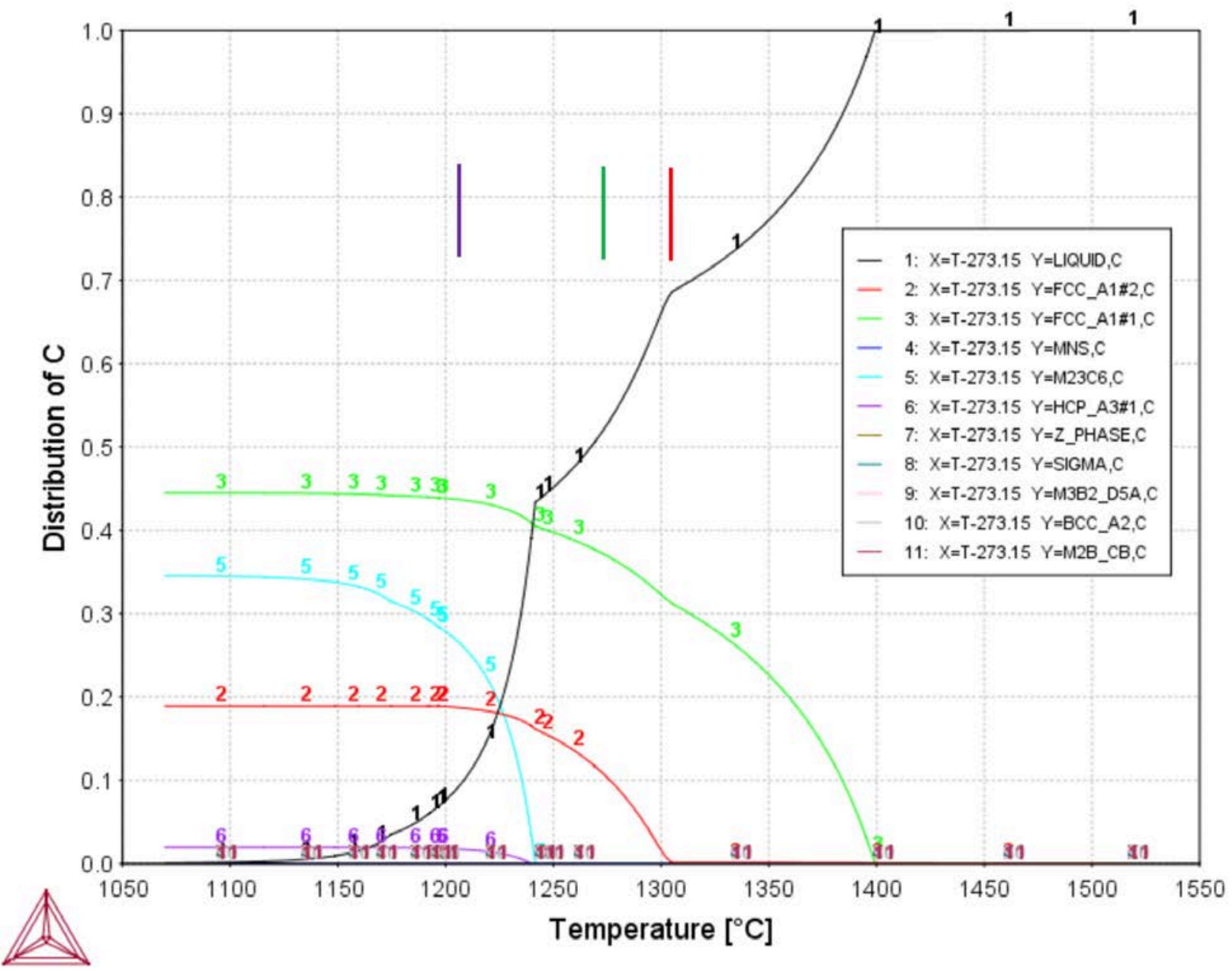

Figure 20. Distribution of $\mathrm{C}$ among the various phases as a function of temperature for Scheil simulation of "average" alloy with 0.006 wt \% P. Red, green, and purple lines represent temperatures for 90, 95, and 99\% solid, respectively. 
2018.08.20.12.41.18

TCFE9: B, C, CR, FE, MN, MO, N, NB, NI, P, S, SI, TI

$T=1790.02, W(C R)=0.208, W(N I)=0.248, W(M N)=1.04 E-2, W(S I)=4 E-3, W(M O)=1.47 E-2, W(N B)=2.5 E-3, W(T I)=6 E-4, W(B)=4 E-5, W(C)=5$. $5 E-4, W(N)=1.7 E-3, W(P)=6 E-5, W(S)=1 E-5, P=1 E 5, N=1$

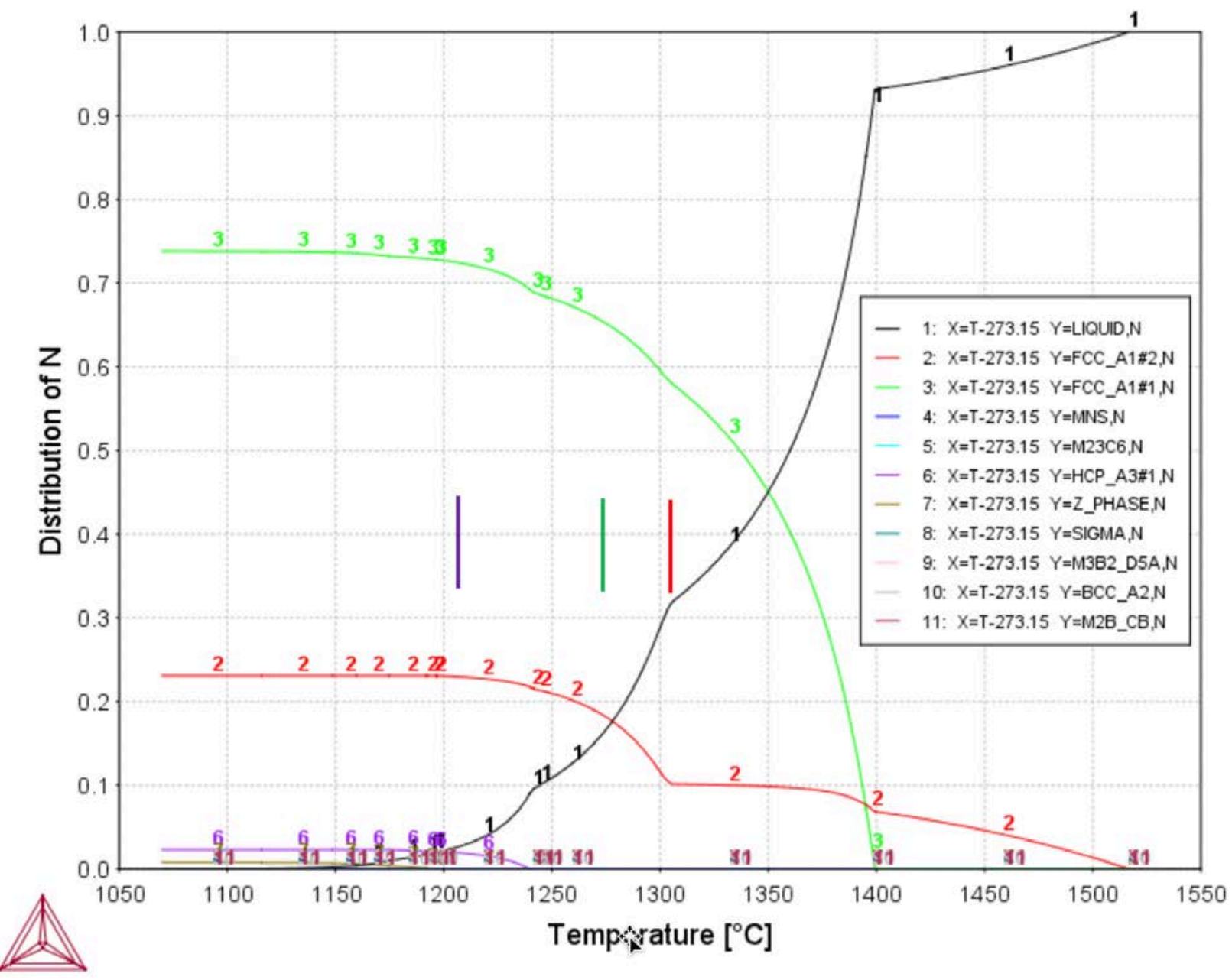

Figure 21. Distribution of $\mathbf{N}$ among the various phases as a function of temperature for Scheil simulation of "average" alloy with 0.006 wt \% P. Red, green, and purple lines represent temperatures for 90, 95, and 99\% solid, respectively. 


\subsection{DISCUSSION ON THE THERMODYNAMIC ANALYSIS}

The goal of this project was to evaluate the solidification behavior of alloy 709 as a function of composition and identify which components have the greatest potential impact on the effective solidification temperature range, which is a reasonable indication of susceptibility for weld solidification cracking. Limited welding tests showed welds with high P level (180 wppm) such as Heat YT709-ORNL cracked during welding while alloys with low P level (20 wppm) such as Heat 120138 did not. The premise was that those elements which extend the solidification temperature range the most may be responsible for the alloy being susceptible to weld solidification cracking. Calculations were made for Scheil solidification conditions. In this type of simulation, the non-equilibrium behavior is exaggerated since back diffusion in the solid during solidification is not allowed. Nevertheless, the actual solidification behavior would be reasonably represented by the behavior predicted under Scheil conditions due to the relatively fast cooling rate associated with weld solidification.

The Scheil simulations were carried out to 0.001 fraction liquid, at which point they were terminated. Although there is no well-established and precise values for the remaining liquid volume fraction for solidification cracking (such values would be expected to be depending on many factors including the stress levels that are present during solidification), it is very likely, from previous studies on weld solidification cracking of stainless steels and nickel based superalloys (Feng, 1993), that at 0.001 fraction liquid (or 0.999 fraction solid), solid phase bridging in the last solidified inter-dendritic region would well developed to resist some stress and avoid cracking. In this regard, carrying out the Scheil solidification simulation to 0.001 fraction liquid remaining provided insight into what factors are most important in influencing the solidification temperature range as well as providing some guidance as to what the constitution of the remaining liquid will be and how susceptible it will be to cracking during welding.

All elements are rejected back into the liquid under Scheil solidification until a solid phase that can absorb any given element becomes stable (or form) and acts as sink for that element, depleting it from the liquid. Clearly, the sooner an element is absorbed into the solid the sooner all the liquid may solidify. The majority of elements ( $\mathrm{Cr}, \mathrm{Ni}, \mathrm{Mn}, \mathrm{Si}, \mathrm{Mo}, \mathrm{Nb}, \mathrm{Ti}, \mathrm{C}, \mathrm{N}$ ) are partitioned to solid phases that are stable at relatively high temperatures (TiN, austenite, $\mathrm{M}_{23} \mathrm{C}_{6}$, and $\mathrm{Nb}(\mathrm{C}, \mathrm{N})$ ). Therefore, these elements are not likely to extend the solidification temperature range on the low temperature side and it is presumed that they are not of primary concern with regard to the weldability. In contrast, S, B, and P are rejected back into the liquid and remain there until lower temperatures (and smaller fraction liquid) where phases that can absorb them become stable.

Of these three potentially harmful alloying additions (with respect to weldability), $\mathrm{S}$ is removed from the liquid at the highest temperatures, once MnS becomes stable. Even when the S levels are high, or the $\mathrm{Mn}$ levels are low, MnS typically forms around $1250^{\circ} \mathrm{C}$ and by the time the temperature reaches $1200^{\circ} \mathrm{C}$ roughly $75 \%$ or more of the $\mathrm{S}$ is removed from the liquid. It is noteworthy that MnS forms even at the lowest $\mathrm{S}$ levels so that a sink that depletes the liquid of $\mathrm{S}$ is always stable.

$\mathrm{B}$ is the second of the 3 residual components $(\mathrm{S}, \mathrm{B}, \mathrm{P})$ to partition from the liquid to solid as the temperature drops and solidification continues. Once again, for all B concentrations studied (0.001 to 0.01 wt \% B), a boride $\left(\mathrm{M}_{3} \mathrm{~B}_{2}\right)$ forms and acts as a sink for $\mathrm{B}$. However, this boride becomes stable at lower temperatures than $\mathrm{MnS}$; the formation temperature is less than $1200^{\circ} \mathrm{C}$. When the $\mathrm{B}$ levels are high, a second boride $\left(\mathrm{M}_{2} \mathrm{~B}\right)$ also becomes stable, at even lower temperatures. B may have an important impact on extending the lower limit of the solidification temperature range, but only at high B levels and low $\mathrm{P}$ levels.

The calculations show that $\mathrm{P}$ has the most significant impact to lower the effective solidus and increase the effective solidification temperature range. This indicates that $\mathrm{P}$ may have the biggest detrimental 
impact on weld solidification cracking. As shown in Figure 4 and Figure 5, austenite can only absorb < $20 \%$ of the P, regardless of whether the P concentration is high or low. This means that most of the P is rejected back into the liquid and results in high concentrations of $\mathrm{P}$ in the remaining liquid. If the $\mathrm{P}$ content is low ( $<0.01 \mathrm{wt} \%$ ), the simulation is terminated before a phosphide becomes stable, but Figure 8 shows that even at such "low" levels, increasing the P content from 0.002 to $0.009 \mathrm{wt} \%$ reduces the Scheil effective solidus by over $200^{\circ} \mathrm{C}$. For high P levels ( $\left.>0.009 \mathrm{wt} \%\right)$, solidification is extended even further until $\mathrm{M}_{3} \mathrm{P}$ phosphide forms, typically around $900^{\circ} \mathrm{C}$. And even when the phosphide forms, higher levels of $\mathrm{P}$ can reduce the effective solidus by hundreds of ${ }^{\circ} \mathrm{C}$ more. Remembering that the Scheil simulation represents the extreme case of solute segregation and non-equilibrium solidification, it is unlikely that the liquid remains stable to the extremely low temperatures found during the simulations. Nonetheless, the simulations show that $\mathrm{P}$ has a very strong and deleterious impact on the solidification behavior and is the most likely suspect that degrades the weldability.

It is important to note that both the Scheil simulation and equilibrium calculations do not consider kinetic effects. Thus, for equilibrium calculations, the actual solidification temperature range may be larger than expected if kinetics are considered, and some minor phases that are predicted may be replaced by others. But the primary result from equilibrium calculations is that the earliest phase to form is TiN and the major phase that solidifies is austenite. Over a range of $\approx 100^{\circ} \mathrm{C}$, most of the austenite solidifies and solidification is typically $90-95 \%$ complete. Kinetics are not likely to affect these two results. In the case of the Scheil solidification simulation, numerous minor phases (sigma phase, ferrite, Z phase, etc.) are predicted to form during the latter stages of solidification. However, these phases are predicted in very small amounts and whether they or some alternate phases form are likely not to be very important as far as the solidification is concerned. The predicted sulfides, borides, and phosphides are probably correct since no other phases have any appreciable solubility for S, B, P except austenite with a modest solubility for all three. Thus, as the temperature decreases, the driving force for formation of sulfides, borides and phosphides will simply increase once the formation temperature has been passed. It is important to note that even if kinetics are included, the sulfides, borides, and phosphides will not form at temperatures above those predicted by the simulation but only at even lower temperatures.

There is only limited experimental data on the weldability of alloy 709. Welding results show only that alloy YT709 was vulnerable to cracking and two other alloys (including 120138) did not crack. The P level in YT709 was high $(0.018 \mathrm{wt} \%)$ and that in the two alloys that did not crack was low (nominally $\leq$ $0.002 \mathrm{wt} \% \mathrm{P}$ ). Thus, the limited experimental data is in line with the predicted negative impact of P. The calculations do not indicate at what level of $\mathrm{P}$ the alloy will be vulnerable to cracking. Further experiments would be necessary to identify the level of P beyond which cracking is likely. Nevertheless, the computational simulation results conducted herein would provide an effective guideline for future experiments to develop welding practices to mitigate the weld solidification cracking in Alloy 709. 


\section{PRELIMINARY WELDING STUDY ON ALLOY 709}

The computational simulation of solidification behavior of Alloy 709 in previous section suggested that $\mathrm{P}$ is a major detrimental factor for weld solidification cracking. An effective solution would be to control the amount of $\mathrm{P}$ in the weld region for defect free weld. To this end, initial screening welding experiment was carried out in FY2018, to explore the possibility of using low P weld wire to weld relatively high P Alloy 709 base metal. The lessons learned in this screening test will be used to formulate the strategy to weld heats of Alloy 709 having wide range of chemistry permissible per ASTM specification planned in next phase of welding process research and development.

\subsection{MATERIAL}

The base metal was the first commercial heat of Alloy 709 produced within US as part of the DOE/ORNL Alloy 709 scale up production program. This commercial heat was produced by G.O. Carlson Inc. in Pennsylvania (Carlson Heat 58776). The Alloy 709 was processed by Argon-Oxygen-Decarburization (AOD), hot rolled and then Solution Annealed (SA) at $1100{ }^{\circ} \mathrm{C}$. The manufacture process of this plate can be found in the report by Natesan, et al (2017). Chemical compositions of this plate are listed in Table 5. Note that this commercial heat has relatively high P level at $0.014 \mathrm{wt} \%$ (140wppm). A section of Alloy 709 AOD SA1100 plate (section ID: 776-4B1-S209) with the size of $277.8 \mathrm{~mm}$ X $101.6 \mathrm{~mm}$ (rolling direction) is used in this preliminary welding study. The plate has nominal thickness of $30.48 \mathrm{~mm}$ (or 1.2in). The as-received plate had surface defects and a thin layer of the top and bottom surface was removed by grinding prior to welding study. Pictures of the as-received the Alloy 709 AOD SA1100 plate and after surface preparation are shown in Figure 22. The plate surface was inspected by dye penetrant (Figure $22 b)$ to ensure all the surface defects were effectively removed.
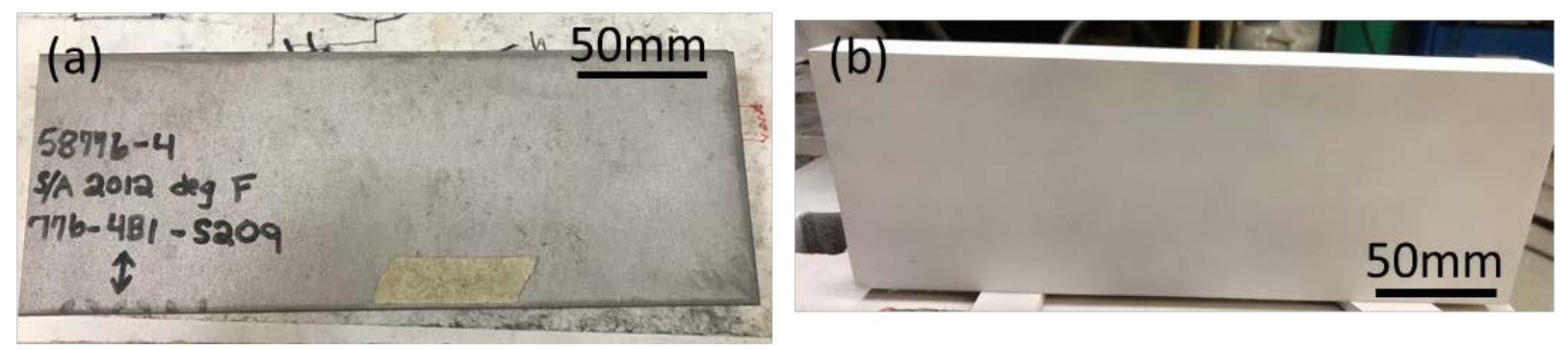

Figure 22. As-received Alloy 709 AOD SA1100 plate (a) and after surface preparation (b)

Table 5. Chemical compositions of the Alloy 709 AOD (heat 58776-4), wt\%

\begin{tabular}{l|l|l|l|l|l|l|l|l|l|l|l|l|l|l}
\hline $\mathrm{C}$ & $\mathrm{Cr}$ & $\mathrm{Cu}$ & $\mathrm{Ni}$ & $\mathrm{Mn}$ & $\mathrm{Mo}$ & $\mathrm{N}$ & $\mathrm{Si}$ & $\mathrm{P}$ & $\mathrm{Ti}$ & $\mathrm{Nb}$ & $\mathrm{B}$ & $\mathrm{Co}$ & $\mathrm{Al}$ & $\mathrm{Fe}$ \\
\hline 0.07 & 19.93 & 0.06 & 24.98 & 0.91 & 1.51 & 0.148 & 0.44 & 0.014 & 0.04 & 0.26 & 0.0045 & 0.02 & 0.02 & Bal. \\
\hline
\end{tabular}

\subsection{WELDING}

The welding wire used in this study was cold drawn from a low P Alloy 709 experimental heat (Heat No 011367-08). The chemical composition of the weld wire used for the V-groove qualification weld is listed in Table 6, with P content of less than $0.002 \mathrm{wt} \%$ (20wppm) (low P). GTAW process was used to make these welds. 
Table 6. Analyzed compositions of the Alloy 709 matching weld wire (Heat 011367-08), wt\%

\begin{tabular}{|c|c|c|c|c|c|c|c|c|c|c|}
\hline $\mathrm{C}$ & $\mathrm{Cr}$ & $\mathrm{Cu}$ & $\mathrm{Ni}$ & $\mathrm{Mn}$ & $\mathrm{Mo}$ & $\mathrm{N}$ & $\mathrm{Si}$ & $\mathrm{P}$ & $\mathrm{Ti}$ & $\mathrm{Al}$ \\
\hline 0.079 & 20.03 & $<0.01$ & 25.05 & 0.87 & 1.48 & 0.156 & 0.28 & $<0.002$ & $<0.01$ & 0.02 \\
\hline $\mathrm{V}$ & $\mathrm{Fe}$ & $\mathrm{W}$ & $\mathrm{Sn}$ & $\mathrm{S}$ & $\mathrm{Co}$ & $\mathrm{B}$ & $\mathrm{Nb}$ & & & \\
\hline$<0.01$ & 51.74 & $<0.01$ & & $<0.0003$ & $<0.01$ & 0.003 & 0.28 & & & \\
\hline
\end{tabular}

Table 7 Welding parameters for V-groove weld

\begin{tabular}{|c|c|c|c|c|c|c|c|c|c|c|}
\hline Pass & welding process & Weld wire & $\begin{array}{l}\text { preheat } \\
\text { interpass }\end{array}$ & Volts $\{\mathrm{V}$ & $\operatorname{Amps}\{A\}$ & $\begin{array}{l}\text { Travel } \\
\text { speed } \\
\text { (ipm) }\end{array}$ & $\begin{array}{c}\text { ASMEIX OW 409.1 } \\
\text { (a) Joules/inch = } \\
\text { (Voltage* Amps*60)/ } \\
\text { (Ipm) }\end{array}$ & $\mathbf{k J} /$ inch & $\begin{array}{l}\text { Wirefeed } \\
\text { speed (ipm) }\end{array}$ & notes \\
\hline 1 & GTAW manual & Low P 011367-08 & $23 \mathrm{C}$ & 9 & 84 & 1.80 & 25200.0 & 25.2 & manual & \\
\hline 2 & GIAW manual & Low P 011367-08 & $50 \mathrm{C}$ & 9 & 120 & 1.90 & 34105.3 & 34.1 & manual & \\
\hline 3 & GTAW Automatic & Low P 011367-08 & $50 \mathrm{C}$ & 10 & 160 & 3.00 & 32000.0 & 32.0 & 20.0 & \\
\hline 4 & GTAW Automatic & Low P 011367-08 & $75 \mathrm{C}$ & 9.8 & 160 & 3.00 & 31360.0 & 31.4 & 22.0 & $1 / 4$ weave \\
\hline 5 & GTAW Automatic & Low P $011367-08$ & $23 \mathrm{C}$ & 9.8 & 160 & 3.00 & 31360.0 & 31.4 & 22.0 & \\
\hline 6 & GTAW Automatic & Low P 011367-08 & $24 \mathrm{C}$ & 9.8 & 160 & 3.00 & 31360.0 & 31.4 & 22.0 & \\
\hline 7 & GTAW Automatic & Low P 011367-08 & $35 \mathrm{C}$ & 9.8 & 160 & 3.00 & 31360.0 & 31.4 & 25 & \\
\hline 8 & GTAW Automatic & Low P 011367-08 & $23 \mathrm{C}$ & 9.8 & 160 & 3.00 & 31360.0 & 31.4 & 25 & \\
\hline 9 & GTAW Automatic & Low P 011367-08 & $50 \mathrm{C}$ & 9.8 & 160 & 3.00 & 31360.0 & 31.4 & 25 & $1 / 4$ weave \\
\hline 10 & GTAW Automatic & Low P 011367-08 & $35 \mathrm{C}$ & 9.8 & 150 & 3.00 & 29400.0 & 29.4 & 22.0 & \\
\hline 11 & GTAW Automatic & Low P $011367-08$ & $70 \mathrm{C}$ & 9.8 & 150 & 3.00 & 29400.0 & 29.4 & 22.0 & \\
\hline 12 & GTAW Automatic & Low P 011367-08 & $55 \mathrm{C}$ & 9.8 & 150 & 3.00 & 29400.0 & 29.4 & 22.0 & $1 / 4$ weave \\
\hline 13 & GTAW Automatic & Low P $011367-08$ & $55 \mathrm{C}$ & 9.8 & 150 & 3.00 & 29400.0 & 29.4 & 22.0 & \\
\hline 14 & GTAW Automatic & Low P 011367-08 & $50 \mathrm{C}$ & 9.8 & 150 & 3.00 & 29400.0 & 29.4 & 22.0 & \\
\hline 15 & GTAW Automatic & Low P 011367-08 & $65 \mathrm{C}$ & 9.8 & 150 & 3.00 & 29400.0 & 29.4 & 22.0 & \\
\hline
\end{tabular}

The welding study was carried out in two steps. In the first step, single bead-on-plate welding trials were performed to determine appropriated welding conditions that would produce cracking-free conditions. A total of 12 bead on plate welds were produced with a wide range of welding parameters.

Based on the evaluation of the bead-on-plate welds, a welding parameter window was selected for a Vgroove butt weld to join two 90 -mm long by $75 \mathrm{~mm}$ wide by $20-\mathrm{mm}$ thick Alloy 709 AOD SA1100 plates. The weld joint configuration is schematically shown in Figure 23. A total of 15 weld passes were used to make the test weld. Detailed welding pass-by-pass parameters are given in Table 7. Pictures of this multi-pass weld using GTAW process are shown in Figure 24. 

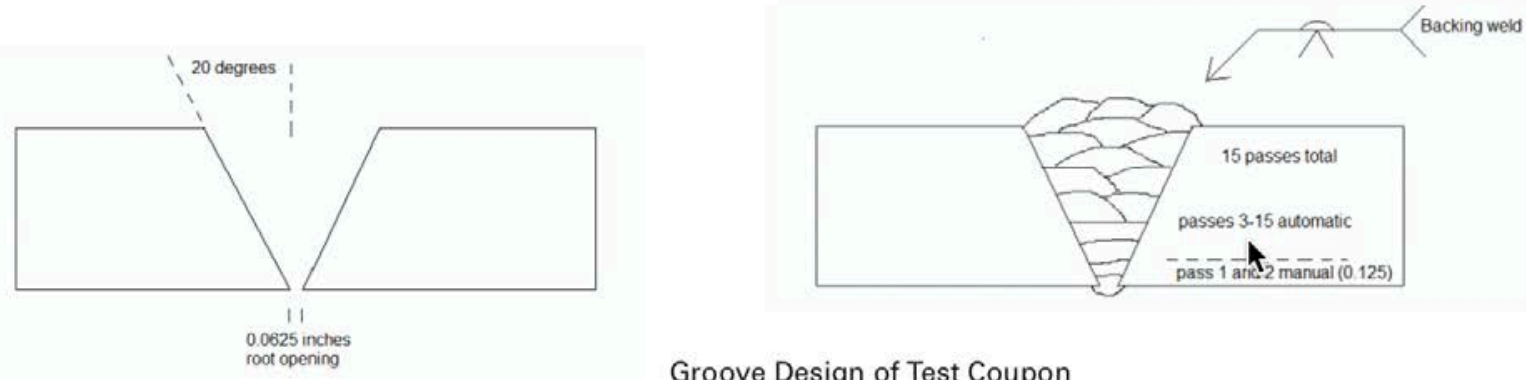

Groove Design of Test Coupon

Figure 23 Groove Design and weld-pass layout of the initial welding experiment

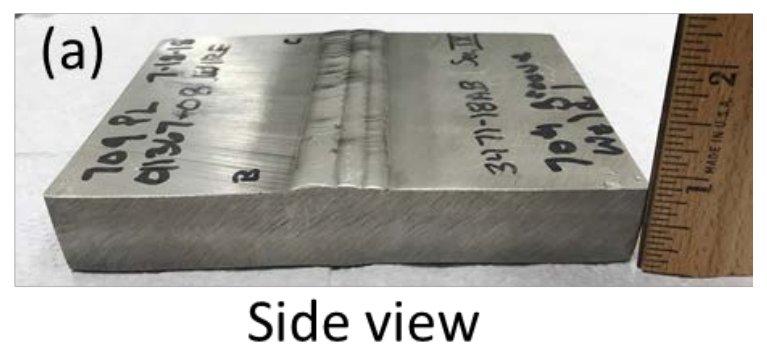

(b)

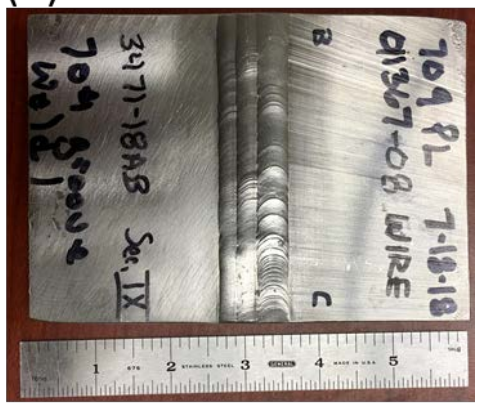

top view

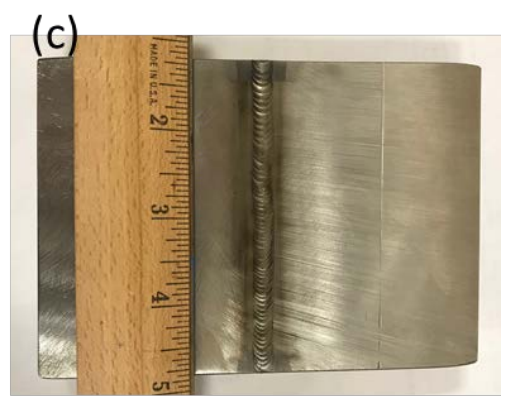

Root pass

Figure 24. Multi-pass V-groove weld for Alloy 709 AOD SA1100 plate

\subsection{QUALIFICATION TESTING OF WELDS FOR ALLOY 709 AOD SA1100 PLATE}

Nondestructive Testing (NDE) was performed on the bead on plate welds and multi-pass V-groove weld on Alloy 709 AOD SA1100 plate. All the bead on plate welds and multi-pass V-groove weld do not show relevant indications of defects through dye penetrant inspection (Figure 25). X-ray radiographic inspection images of these welds are presented in Figure 26, and the inspection shows that it passes ASME IX QW 191.1.2.2 qualification requirements.

Plunge side bend tests were performed on four specimens from the multi-pass V-groove weld. Pictures of all the tested specimens are show in Figure 27. A small crack was found near the fusion line in one of the four specimens after bending tests, but the cracks are less than $3.175 \mathrm{~mm}$ (or 1/8-in), the code allowable 
size. The bead on plate welds and multi-pass V-groove weld have therefore passed the ASME SEC IX qualification evaluation.

Additional mechanical testing including cross-weld tensile, creep and/or creep fatigue is planned and will be summarized in future reports.
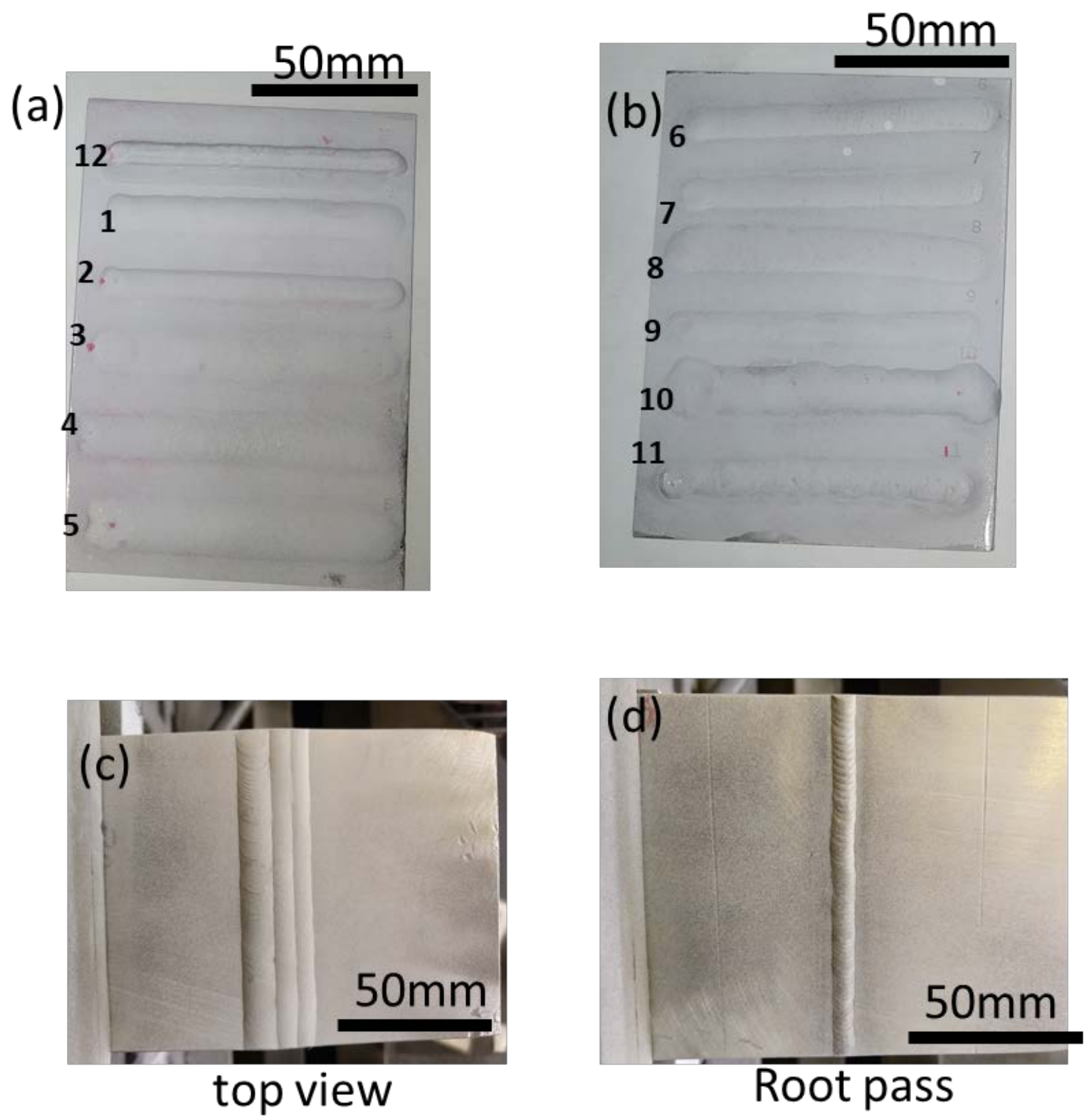

Figure 25. Dye penetrant inspection of the bead on plate welds (a, b) and multi-pass V groove weld (c, d) 

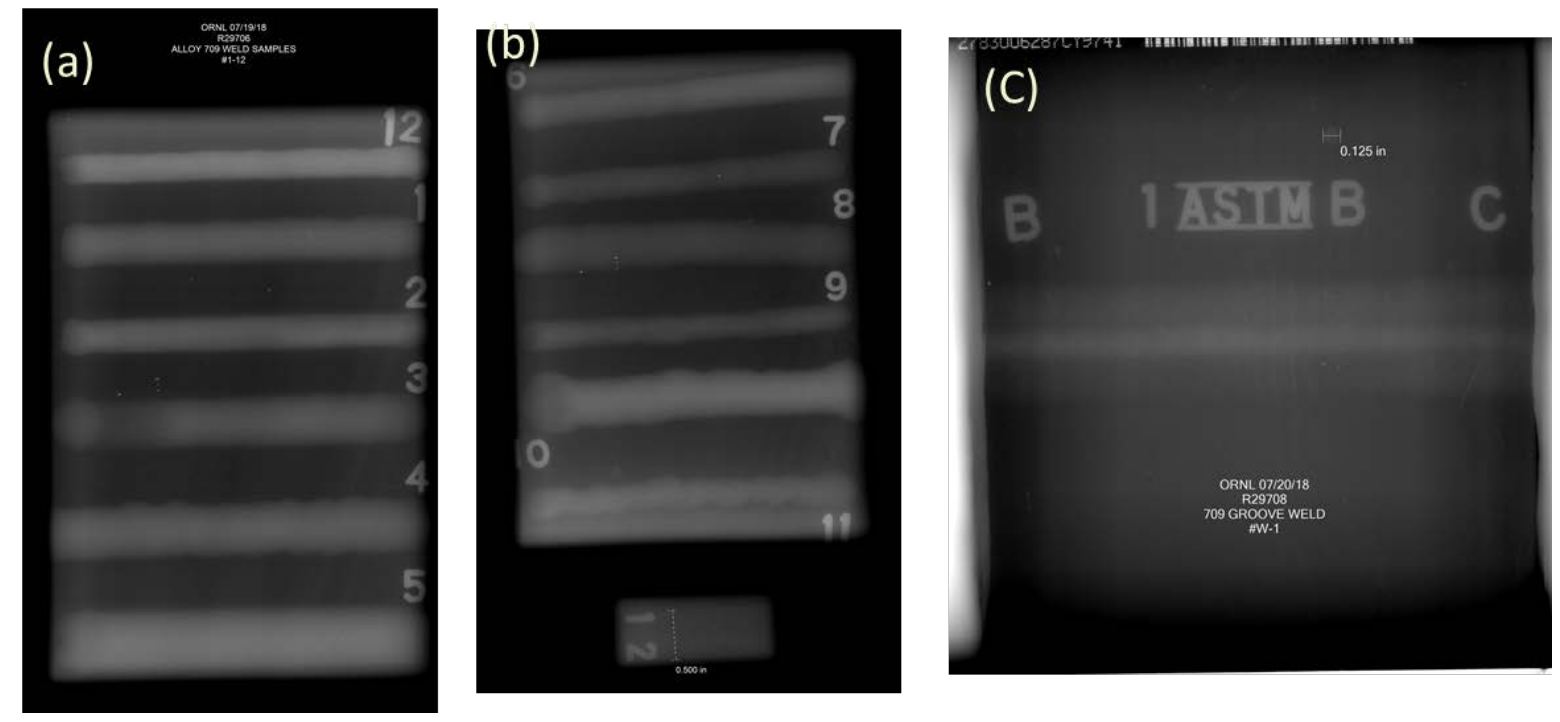

Figure 26. X-ray inspection of the bead on plate welds (a, b) and multi-pass V groove weld (c)

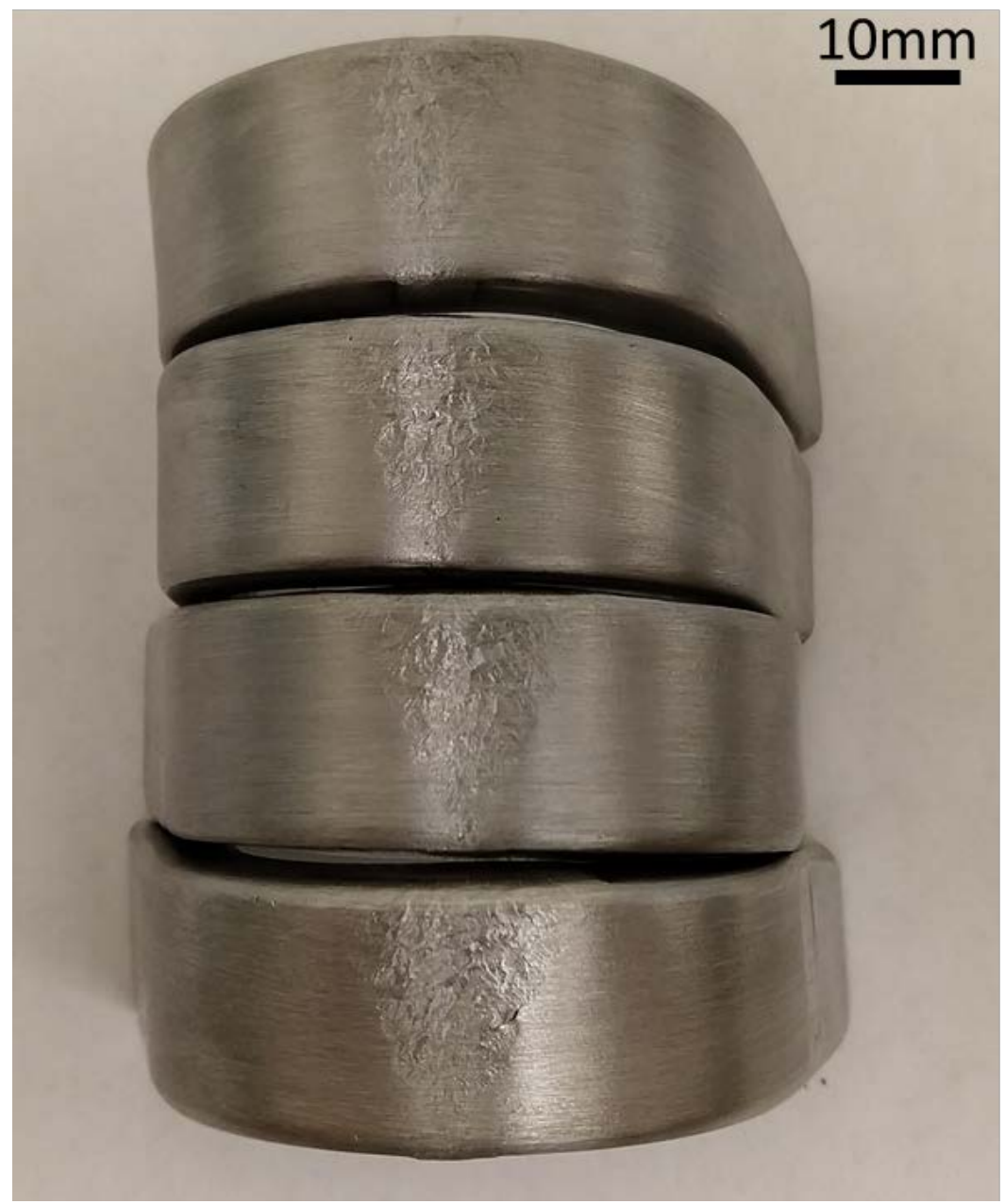

Figure 27. Side bend test specimens of the multi-pass V groove weld on Alloy 709 AOD SA1100 plate 


\section{SUMMARY}

Computational thermodynamic modeling of the non-equilibrium Scheil solidification relevant to welding revealed the followings.

- All elements are rejected back into the liquid under Scheil solidification until a solid phase that can absorb the element becomes stable (or formed) and acts as sink for that element, depleting it from the liquid. The majority of elements ( $\mathrm{Cr}, \mathrm{Ni}, \mathrm{Mn}, \mathrm{Si}, \mathrm{Mo}, \mathrm{Nb}, \mathrm{Ti}, \mathrm{C}, \mathrm{N}$ ) are partitioned to solid phases formed at relatively high temperatures (TiN, austenite, $\mathrm{M}_{23} \mathrm{C}_{6}$, and $\mathrm{Nb}(\mathrm{C}, \mathrm{N})$ ). Therefore, these elements are not likely to extend the solidification temperature range on the low temperature side and it is presumed that they are not of primary concern with regard to the weldability.

- In contrast, S, B, and P are rejected back into the liquid and remain there until lower temperatures (and smaller fraction liquid) where phases that can absorb them become stable. Of these three potentially harmful alloying additions (with respect to weldability), $\mathrm{S}$ is removed from the liquid at the highest temperatures, as MnS forms. Even when the S levels are high, or the Mn levels are low, MnS typically forms around $1250^{\circ} \mathrm{C}$ and by the time the temperature reaches $1200^{\circ} \mathrm{C}$ roughly $75 \%$ or more of the $\mathrm{S}$ is removed from the liquid. It is noteworthy that $\mathrm{MnS}$ forms even at the lowest $\mathrm{S}$ levels so that a sink that depletes the liquid of $\mathrm{S}$ is always stable.

- For all B concentrations studied (0.001 to 0.01 wt \% B), a boride $\left(\mathrm{M}_{3} \mathrm{~B}_{2}\right)$ forms and acts as a sink for $\mathrm{B}$. However, this boride becomes stable at lower temperatures than MnS; the formation temperature is less than $1200^{\circ} \mathrm{C}$. When the $\mathrm{B}$ levels are high, a second boride $\left(\mathrm{M}_{2} \mathrm{~B}\right)$ also becomes stable, at even lower temperatures. B may have an important impact on extending the lower limit of the solidification temperature range, but only at high B levels and low P levels.

- Among all the alloying elements and impurity elements in Alloy 709, $\mathrm{P}$ has a very strong and deleterious impact on the solidification behavior and is the most likely suspect that degrades the weldability. It has the most significant impact to lower the effective solidus and increase the effective solidification temperature range. This indicates that $\mathrm{P}$ may have the biggest detrimental impact on weld solidification cracking. Austenite can only absorb $<20 \%$ of the P, regardless of whether the $\mathrm{P}$ concentration is high or low. Thus, most of the $\mathrm{P}$ is rejected back into the liquid and results in high concentrations of $\mathrm{P}$ in the remaining liquid. For P levels great than $0.009 \mathrm{wt} \%$ (90 wppm), solidification is extended until $\mathrm{M}_{3} \mathrm{P}$ phosphide forms, typically around $900^{\circ} \mathrm{C}$. Higher levels of $\mathrm{P}$ can reduce the effective solidus by hundreds of ${ }^{\circ} \mathrm{C}$ more, as low as $700^{\circ} \mathrm{C}$ at $0.02 \mathrm{wt} \%$ (200wppm), as predicted by the Scheil solidification model.

The findings from the computational solidification modeling analysis provides the basis to develop strategies to weld heats of Alloy 709 having wide range of chemistry without weld solidification cracking to support code qualification. One of the strategies is to use low P level matching weld wire to weld relatively high P Alloy 709. Initial screening welding experiment using this strategy has been successful a Section IX qualified weld has been fabricated on the first commercial heat (Carlson 58776) having relatively high P (140 wppm) using a 20 wppm low P matching weld wire. Inspection and side bend tests on this multi-pass weld confirmed that it passed the ASME Section IX qualification requirement.

Strategies to fabricate Section IX qualified welds for Alloy 709 with wide range of chemistry permissible per ASTM A213-15C specification for both base metal and weld filler metal are being explored in next phase of welding process research and development. 
This report fulfills the FY18 milestone M3NT-18OR050502023 - "Complete the evaluation of the effect of alloy chemistry on the susceptibility of weld solidification cracking of Alloy 709 weldment and fabricate initial test welds” under the ORNL work package NT-18OR05050202- "A709 Development ORNL”. 


\section{REFERENCES}

ASME Boiler and Pressure Code, Section IX, 2017 edition, “Qualification Standard for Welding, Brazing, and Fusing Procedures; Welders; Brazers; and Welding, Brazing, and Fusing Operators”.

ASTM A213-15C, "Standard Specification for Seamless Ferritic and Austenitic Alloy-Steel Boiler, Superheater, and Heat-Exchanger Tubes”, ASTM International, West Conshohocken, PA, 2015, www.astm.org.

Busby, J. T., S. Byun, R. Klueh, P. Maziasz, and J. Vitek, K. Natesan, M. Li, R. Wright, S. Maloy, M. Toloczko, A. Motta, B. D. Wirth, G. R. Odette, and T. Allen, "Candidate Developmental Alloys for Improved Structural Materials for Advanced Fast Reactors,” ORNL/GNEP/LTR-2008-023, March 2008.

Feng, Z. 1993. "A methodology for quantifying the thermal and mechanical conditions for weld metal solidification cracking.” PhD dissertation, The Ohio State University.

Natesan, K., Zhang, X., Sham, T.-L., and H. Wang, "Report on the completion of the procurement of the first heat of Alloy 709”, ANL-ART-89, Argonne National Laboratory, June 2017.

NIPPON STEEL \& SUMITOMO STEEL, NF709 Material Data Sheet, (2013) http://www.tubular.nssmc.com/product-services/specialty-tube/product/nf709.

Sham, T.-L. and K. Natesan, “Code Qualification Plan for an Advanced Austenitic Stainless Steel, Alloy 709, for Sodium Fast Reactor Structural Applications”, in International Conference on Fast Reactors and Related Fuel Cycles. 2017: Yekaterinburg, Russian Federation, IAEA-CN-245-74.

Y. Yamamoto, 2014, Unpublished data, Oak Ridge National Laboratory 
ORNL/TM-2018/965

\section{ELECTRONIC DISTRIBUTION}

$\begin{array}{lll}\text { Name } & \text { Affiliation } & \text { Email } \\ \text { Lesica, S. } & \text { DOE-NE } & \text { sue.lesica@nuclear.energy.gov } \\ \text { Sowinski, T. E.. } & \text { DOE } & \text { thomas.sowinski@nuclear.energy.gov } \\ \text { Grandy, C. } & \text { ANL } & \text { cgrandy@anl.gov } \\ \text { Hill, R.N. } & \text { ANL } & \text { bobhill@anl.gov } \\ \text { Chen, J. } & \text { ORNL } & \text { linl@ornl.gov } \\ \text { Lin, L. } & \text { ORNL } & \text { messner@anl.gov } \\ \text { Messner, M.C. } & \text { ANL } & \text { ssham@anl.gov } \\ \text { Sham, T.-L. } & \text { ANL } & \text { wangy3@ornl.gov } \\ \text { Wang, Y. } & \text { ORNL } & \text { richard.wright@inl.gov } \\ \text { Wright, R.N. } & \text { INL } & \end{array}$

